\title{
fNIRS-based Neurorobotic Interface for gait rehabilitation
}

\author{
Rayyan Azam Khan ${ }^{1}$, Noman Naseer ${ }^{1 *}$ (D), Nauman Khalid Qureshi ${ }^{2}$, Farzan Majeed Noori ${ }^{3}$, Hammad Nazeer ${ }^{1}$ \\ and Muhammad Umer Khan ${ }^{1}$
}

\begin{abstract}
Background: In this paper, a novel functional near-infrared spectroscopy (fNIRS)-based brain-computer interface $(\mathrm{BCl})$ framework for control of prosthetic legs and rehabilitation of patients suffering from locomotive disorders is presented.

Methods: fNIRS signals are used to initiate and stop the gait cycle, while a nonlinear proportional derivative computed torque controller (PD-CTC) with gravity compensation is used to control the torques of hip and knee joints for minimization of position error. In the present study, the brain signals of walking intention and rest tasks were acquired from the left hemisphere's primary motor cortex for nine subjects. Thereafter, for removal of motion artifacts and physiological noises, the performances of six different filters (i.e. Kalman, Wiener, Gaussian, hemodynamic response filter (hrf), Band-pass, finite impulse response) were evaluated. Then, six different features were extracted from oxygenated hemoglobin signals, and their different combinations were used for classification. Also, the classification performances of five different classifiers (i.e. k-Nearest Neighbour, quadratic discriminant analysis, linear discriminant analysis (LDA), Naïve Bayes, support vector machine (SVM)) were tested.
\end{abstract}

Results: The classification accuracies obtained from SVM using the hrf were significantly higher $(p<0.01)$ than those of the other classifier/ filter combinations. Those accuracies were 77.5, 72.5, 68.3, 74.2, 73.3, 80.8, 65, 76.7, and $86.7 \%$ for the nine subjects, respectively.

Conclusion: The control commands generated using the classifiers initiated and stopped the gait cycle of the prosthetic leg, the knee and hip torques of which were controlled using the PD-CTC to minimize the position error. The proposed scheme can be effectively used for neurofeedback training and rehabilitation of lower-limb amputees and paralyzed patients.

Keywords: Functional near-infrared spectroscopy, Brain-computer interface, Primary motor cortex, Hemodynamic response filter, Linear discriminant analysis, Support vector machine, Computed torque controller

\section{Background}

Neurological disability due specifically to stroke or spinal cord injury can profoundly affect the social life of paralyzed patients [1-3]. The resultant gait impairment is a large contributor to ambulatory dysfunction [4]. In order to regain complete functional independence, physical rehabilitation remains the mainstay option, owing to the significant expense of health care and the redundancy of therapy sessions. Such devices are developed as alternatives to traditional, expensive and time-consuming exercises

\footnotetext{
* Correspondence: noman@pusan.ac.kr

'Department of Mechatronics Engineering, Air University, Islamabad, Pakistan Full list of author information is available at the end of the article
}

in busy daily life. In the past, similar training sessions on treadmills performed using robotic mechanisms have shown better functional outcomes [1, 2, 5-7]. However, these devices have limitations particular to given research and clinical settings. Therefore, wearable upper- and lower-limb robotic devices have been developed [7, 8], which are used to assist users by actuating joints to partial or complete movement using brain intentions, according to individualpatient needs.

To date, various noninvasive modalities including functional magnetic resonance imaging (fMRI), electroencephalography (EEG) and functional near-infrared spectroscopy ( $\mathrm{fNIRS)}$ have been used to acquire brain signals. fNIRS is a 
relatively new modality that detects brain intention with reference to changes in hemodynamic response. Its fewer artifacts, better spatial resolution and acceptable temporal resolution make it the choice for comprehensive and promising results in, for example, rehabilitation and mental task applications [9-20]. The main brain-computer interface $(\mathrm{BCI})$ challenge in this regard is to extract useful information from raw brain signals for control-command generation [21-23]. Acquired signals are processed in the following four stages: preprocessing, feature extraction, classification, and command generation. In preprocessing, physiological and instrumental artifacts and noises are removed [24, 25]. After this filtration stage, feature extraction proceeds in order to gather useful information. Then, the extracted features are classified using different classifiers. Finally, the trained classifier is used to generate control commands based on a trained model [23]. Figure 1 shows a schematic of a BCI.

Previous studies on signal-acquisition techniques have shown promising outcomes, but rehabilitation applications require the best possible results $[3,4,26]$. In Eliana et al. [27], a treadmill was used to acquire EEG-based walking brain signals for sensorimotor applications with $87 \%$ accuracy. In Andreea et al. [28], EEG-based walking-intention signals were detected for stroke patients with an accuracy of $82 \%$. Their data indicated that patients highly motivated for rehabilitationrelated tasks tended to have higher success rates. In Naseer et al. [29], two-class motor imagery movements were analyzed using an LDA classifier. With their employed modality, fNIRS, the best features were found to be signal mean (SM) and signal slope (SS). By reducing the task period to between 2 and $7 \mathrm{~s}$, the accuracies were improved to 77.56 and $87.28 \%$, respectively. In Rea et al. [30], lower-limb movement for gait rehabilitation was detected based on fNIRS signals. They were able to acquire fNIRS signals in their chronic stroke patients during preparation for hip movement with $67.77 \pm 11.35 \%$ accuracy. In Zhao et al. [31], a prosthetic controller was proposed for a bipedal robot. A walking gait pattern was found for the robot mechanism while an online optimized trans-femoral prosthesis control method (i.e. control Lyapunov function (CLF)based quadratic programs (QPs) with variable impedance control) was tested on the knee and ankle joints of the prosthetic device. Azimi et al. [32] proposed stable robust adaptive impedance control for a prosthetic limb. A regressor-based nonlinear robust model was designed with reference to an adaptive impedance controller. In Richter et al. [33], dynamic modeling and simulation-based control of a prosthesis were performed, focusing on two-degree-of-freedom robot modeling, parametric estimation and feedback control for mimicking of hip motions. Perrey [34] explored neural gait control using fNIRS, specifically looking at the relevant cortical areas. In Venkatakrishnan [35], meanwhile, examined and discussed a rehabilitation-based brain machine interface (BMI) application for stoke patients.

The previous literature on the subject of rehabilitation shows that classification accuracy in the online setting is compromised by, among other problems, false triggering. Therefore, we also present a method to ensure that a correct command is always sent to a prosthetic leg (details are given in Section 3.1.1).

In this study, we acquired fNIRS walking signals of healthy subjects. Raw signals might contain noises and artifacts that can be removed using adaptive or bandpass filtering $[25,36]$. In order to avoid such noises, the following six filters were compared for signal processing: Kalman, Wiener, finite impulse response (FIR), hemodynamic response (hrf), Band-pass, and Gaussian. Five classifiers, namely quadratic discriminant analysis (QDA), linear discriminant analysis (LDA), support vector machine (SVM), k-Nearest Neighbour (KNN), and

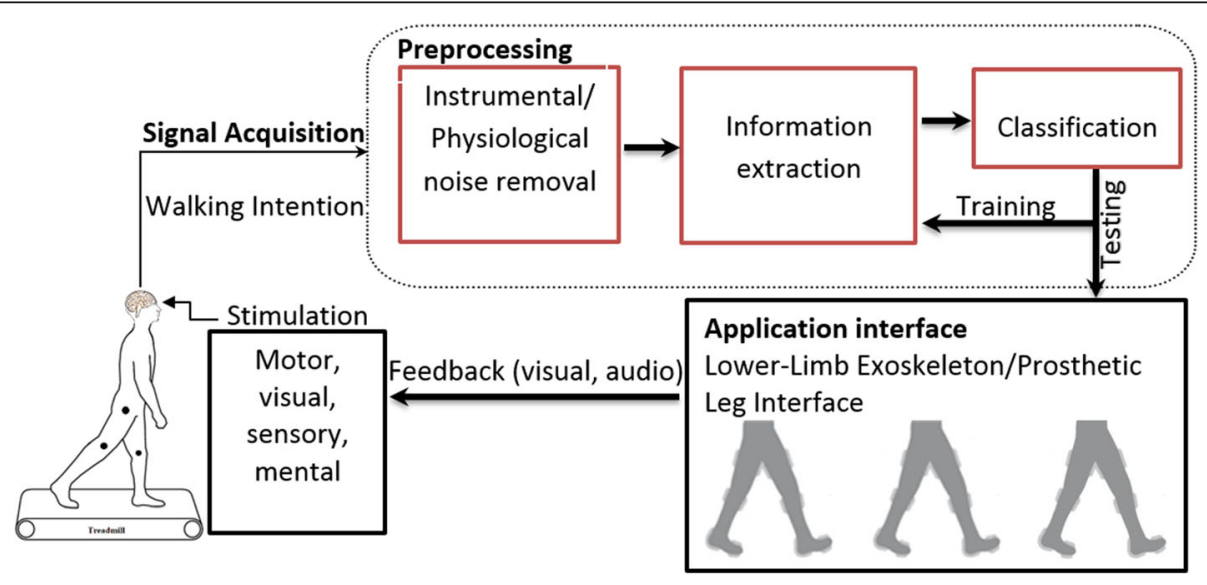

Fig. 1 Schematic of $\mathrm{BCl}$ 
Naïve Bayes (NB), were analyzed for acquisition of maximum classification accuracies. For offline BCI, SVM showed greater statistical significance $(p<0.01)$ as compared with the other classifiers; however, in consideration of execution delay and minimum computation cost, for online $\mathrm{BCI}$, we used LDA with combinations of six features: SS, SM, signal peak (SP), signal kurtosis (KR), signal skewness (SK), and signal variance (SV). Walking intention was then used to initiate and stop the gait cycle of the proposed prosthetic leg model. For minimization of discomfort, a nonlinear computed torque controller (CTC) with gravity compensation was applied to two active joints in the hip and knee and one passive joint in the ankle for position control and reduction of error in waking patterns [37-39]. Given its effective simulation of classical limb-type and mobile robotics, the Peter Corke ${ }^{\circ}$ robotics tool box was used to minimize position error [40]. The proposed system is applicable not only to paralyzed patients but also, and with little modification, to amputees and elderly people.

\section{Method}

\section{Experimental protocol}

In this study we used dynamic near-infrared optical tomography (DYNOT; NIRx Medical Technologies, NY, USA). DYNOT operates on two wavelengths, 760 and $830 \mathrm{~nm}$. The machine sampling frequency used for signal acquisition was $1.81 \mathrm{~Hz}$. Prior to the experimentation, verbal consent was obtained from all of the subjects. Nine healthy male members having normal or corrected-to-normal vision were recruited for the study. All were right-handed and of $30 \pm 3$ median age. As discussed in the literature, the best region in which to acquire fNIRS-based BCI signals for self-paced walking is the primary motor cortex (M1); thus, signals were acquired from the M1 in the left hemisphere [34, 41-43]. The participants had no history of motor disability or any visual, neurological disorder. All of the experiments were performed in accordance with latest Declaration of Helsinki.

\section{Experimental paradigm}

In accordance with the literature [22, 41], the subjects were asked to take a rest for 30 s in a quiet room before the start of each experiment. The experimental paradigm consisted of 10 s walking on a treadmill followed by 20 s rest while standing on the treadmill. All of the subjects started their walk with the right leg. For each subject, 10 trials were performed, and a 30s rest was given at the end of each experiment for baseline correction of the signals. Excluding the initial and final rest, the total length of each experiment was $300 \mathrm{~s}$ for each subject. Self-paced walking, which is to say, according to each subject's comfort level, was performed. Figure 2 shows the experimental paradigm.

\section{Experimental configuration}

To acquire fNIRS-based walking brain signals, 9 optodes were placed on the left hemisphere of the M1, among which 4 were Near Infrared (NI) light detectors and 5 were sources. Twelve (12) channels were formed as per the defined configuration, and a $3 \mathrm{~cm}$ distance was maintained between a source and a detector. The source/detector configuration with channels is shown in Fig. 3.

\section{Signal acquisition}

The Modified Beer-Lambert Law (MBLL) was used to convert raw optical density signals into oxy- and deoxy-hemoglobin concentration changes $\left(\Delta c_{\mathrm{HbO}}(t)\right.$ and $\left.\Delta c_{\mathrm{HbR}}(t)\right)[18,44]$.

$$
\left[\frac{\Delta c_{H b O}(t)}{\Delta c_{H b R}(t)}\right]=\frac{\left[\begin{array}{ll}
\alpha_{H b O}\left(\lambda_{1}\right) & \alpha_{H b R}\left(\lambda_{1}\right) \\
\alpha_{H b O}\left(\lambda_{2}\right) & \alpha_{H b R}\left(\lambda_{2}\right)
\end{array}\right]^{-1}\left[\begin{array}{l}
\Delta A\left(t, \lambda_{1}\right) \\
\Delta A\left(t, \lambda_{2}\right)
\end{array}\right]}{d * l}
$$

Where $l$ is the source and detector distance, $d$ is the curved path length factor, $A\left(t, \lambda_{1}\right), A\left(t, \lambda_{2}\right)$ is the absorption at two different instants, $\alpha_{H b R}(\lambda), \alpha_{H b O}(\lambda)$ are the extinction coefficient of $\mathrm{HbO}$ and $\mathrm{HbR}$ in $\left[\mu \mathrm{M}^{-1} \mathrm{~cm}^{-1}\right]$, and $\Delta c_{H b R}(t), \Delta c_{H b O}(t)$ are the concentration changes of $\mathrm{HbR}$ and $\mathrm{HbO}$ in $[\mu \mathrm{M}]$.

\section{Signal processing}

The brain signals acquired were filtered using different filters to attain maximum accuracy. To eliminate high- and low-frequency physiological or instrumental noises such as heartbeat $(1-1.5 \mathrm{~Hz})$, respiration $(\sim 0.5 \mathrm{~Hz})$, artifacts, blood pressure (Mayer waves), and others, signals were filtered with a low-pass filter having cut-off frequency of $0.5 \mathrm{~Hz}$ and a high-pass filter having cut-off frequency of

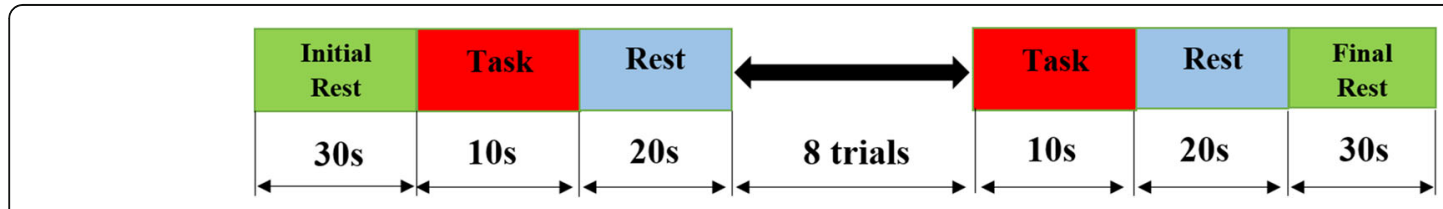

Fig. 2 Experimental paradigm 


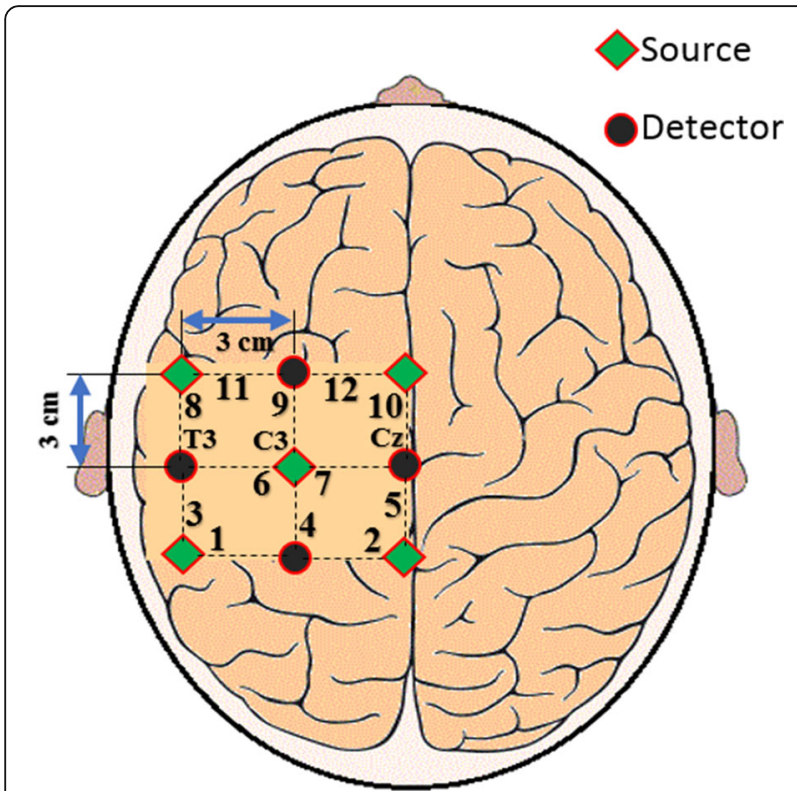

Fig. 3 Optode placement with channel configuration on left hemisphere of motor cortex [82]. T3, C3, and Cz are reference points in the international 10-20 system short-time Fourier series was implemented as in [46]. Gaussian and hrf filters were applied using NIRS-SPM toolbox developed by [17]. These filters consider Gaussian kernel and canonical hemodynamic response function, respectively, for smoothing of the time-series signal. Figure 4 shows the filtered $\mathrm{HbO}$ signals of channel 1 for subject 1 using all six filters.

\section{Feature extraction}

In this study, six different features were extracted using spatial average of all 12 measured channel [47]. Six statistical properties (SM, SK, KR, SS, SP, SV) of the averaged signal were calculated for the entire task and rest sessions. For SM, the calculation was as follows:

$$
S M=\frac{1}{N} \sum_{i=1}^{N} Z_{i}
$$

where $N$ is the total number of observations and $Z_{i}$ represents the $\Delta c_{H b O}(t)$ across each observation. SK was calculated according to the asymmetry of the signal values around the mean relative to a normal distribution:

$$
\operatorname{skew}(Z)=E\left[\left(\frac{Z-\mu}{\sigma}\right)^{3}\right]
$$

$0.01 \mathrm{~Hz}$, in accordance with the literature [23]. The sponse (FIR), Kalman, Wiener, hemodynamic response (hrf) and Gaussian. Butterworth and FIR filters were 4th order. Kalman filter with a discrete model was implemented [45], whereas time-varying Wiener filter, based on where $\sigma$ is the standard deviation of $Z$ and $E$ is expected value of $Z$. KR was calculated as:

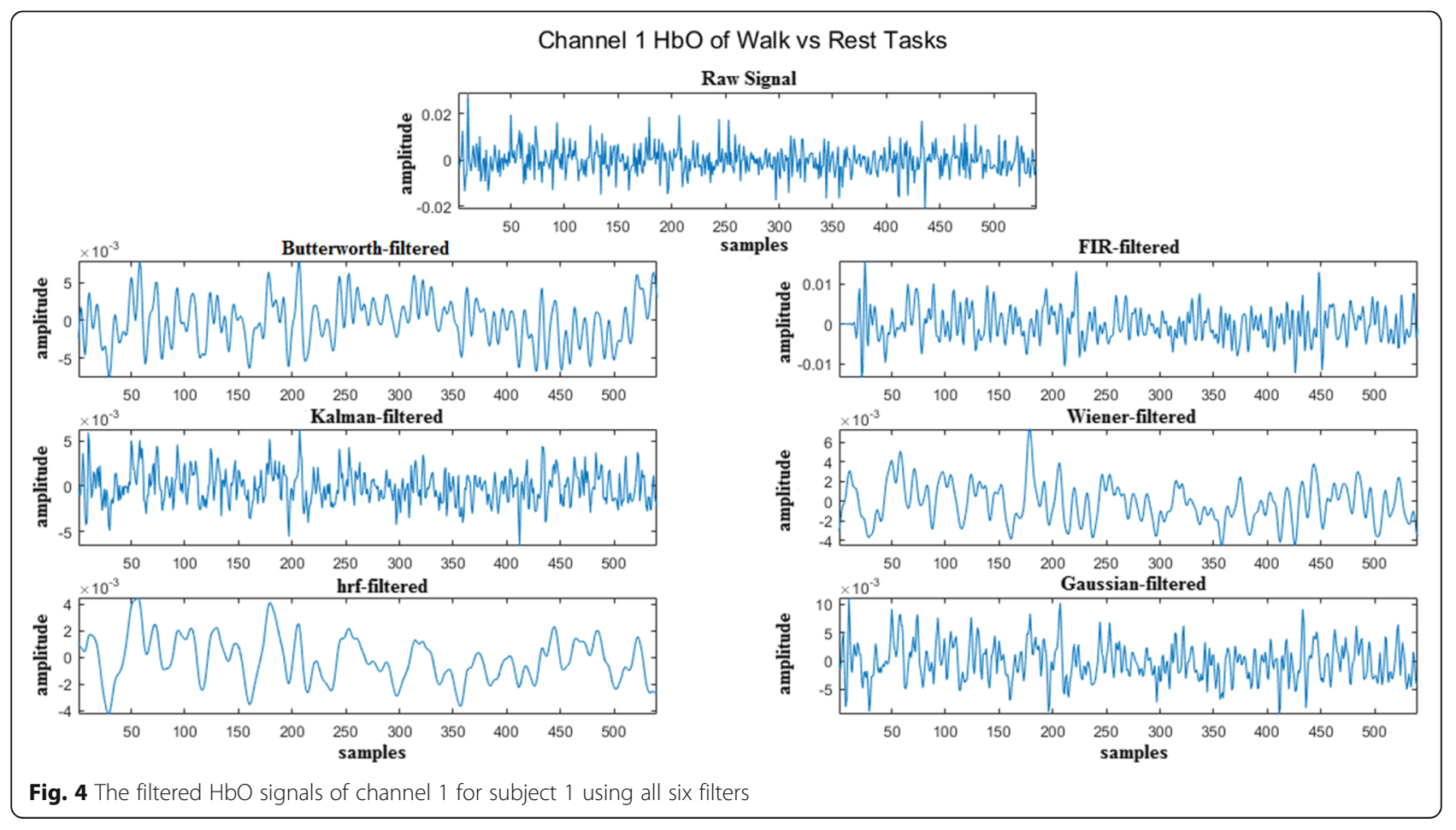




$$
\operatorname{kurt}(Z)=E\left[\left(\frac{Z-\mu}{\sigma}\right)^{4}\right]
$$

SS was calculated by using the polyfit function in $\mathrm{MATLAB}^{\circ}$, which fits a line to all data points. To calculate SP, the max function in $\mathrm{MATLAB}^{\circ}$ was used. The features are rescaled between 0 and 1 using the equation

$$
x^{\prime}=\frac{x-\min (x)}{\max (x)-\min (x)}
$$

where $x^{\prime}$ is the rescaled feature, $x \in R^{n}$ denotes the original feature values, $\min x$ is the smallest value, and $\max$ $x$ is the largest value. Figure 5 provides the scatter plot of subject 1 for all features.

\section{Classification}

\section{SVM}

SVM is used for offline BCI classification. Due to its non-linear nature moreover, it is widely employed to achieve high classification performance [48-51]. Thus, by using SVM, high-dimensional data can be scaled and errors can be explicitly controlled. In order to attain the maximum classification accuracy, SVM creates hyperplanes to maximize the margins between the classes. The vectors known as hyperplanes are named support vectors [23, 48-52].

The optimal solution $\mathrm{r}^{*}$ is obtained by minimizing the following cost function between a hyperplane and the nearest training data points.

Minimize

$$
\frac{1}{2}\|w\|^{2}+C \sum_{i=1}^{n} \xi_{i}
$$

Subject to

$$
y_{i}\left(w^{T} x_{i}+b\right)^{3} \geq 1-\xi_{i}, \quad \xi_{i} \geq 0
$$

where $w^{T}, x_{i} \in R^{2}$ and $b \in R^{1},\|w\|^{2}=w^{T} w, C$ is the tradeoff parameter between the margin and the error, $\xi_{i}$ is the measured training data, and $y_{i}$ is the class label for the $\mathrm{i}^{\text {th }}$ sample. We used a third-degree polynomial kernel function with $C=0.5$. 10-fold cross-validation was then applied for estimation of classification accuracies.

\section{LDA}

LDA is the most common classifier used for pattern recognition in BCI offline and online systems, due to its low computational cost and high-speed performance. To separate classes from each other, LDA finds the projection to a line so that the two classes are well separated $[47,53]$. LDA's main objective is to perform dimensionality reduction, for which it minimizes the variance within each projected class and maximizes the distance between the means of projected classes.

This is done by maximizing the Fisher's criterion given below:

$$
J(v)=\frac{v^{T} S_{b} v}{v^{T} S_{w} v}
$$

where $S_{b}$ and $S_{w}$ are the between-class and within-class scatter matrices defined as
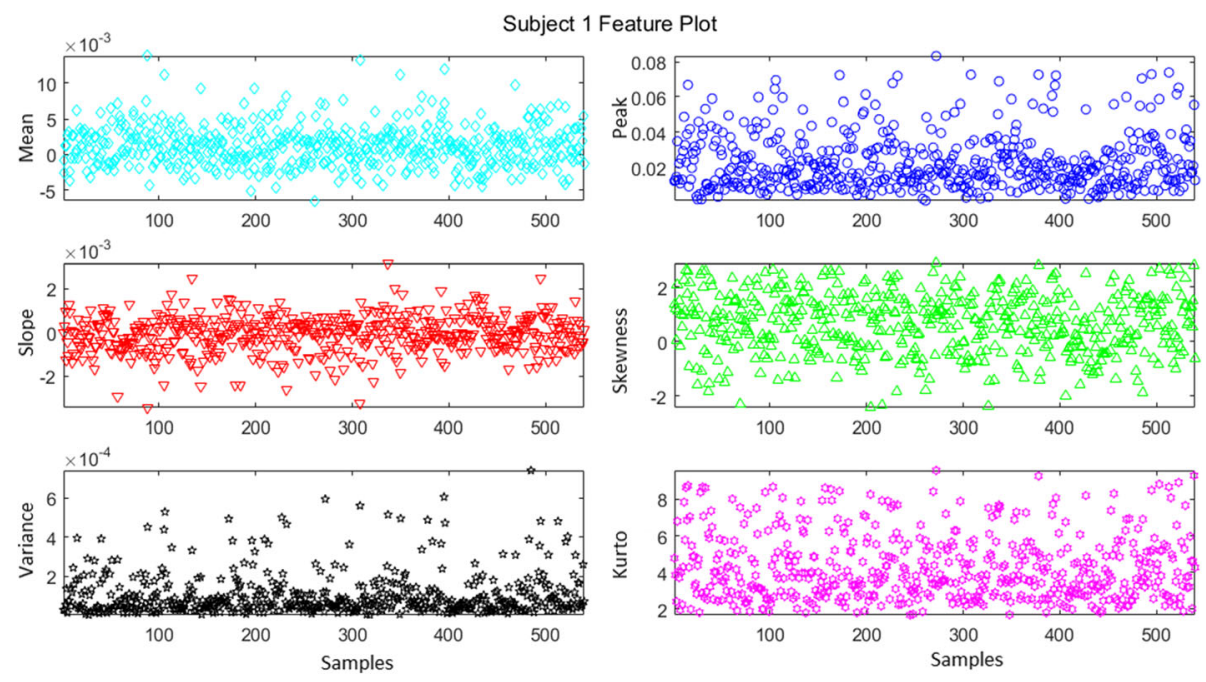

Fig. 5 Scatter plot of features for subject 1 


$$
\begin{aligned}
& S_{\mathrm{b}}=\left(m_{1}-m_{2}\right)\left(m_{1}-m_{2}\right)^{\mathrm{T}} \\
& S_{\mathrm{w}}=\sum_{x_{n} \in 1}\left(x_{n}-m_{1}\right)\left(x_{n}-m_{2}\right)^{\mathrm{T}}+\sum_{x_{n} \in 2}\left(x_{n}-m_{1}\right)\left(x_{n}-m_{2}\right)^{\mathrm{T}}
\end{aligned}
$$

where $m_{1}$ and $m_{2}$ represent the group means of classes $\mathrm{C}_{1}$ and $\mathrm{C}_{2}$, respectively, and $x_{n}$ denotes the samples. A vector $v$ that satisfies (9) can be reformulated, as a generalized eigenvalue problem, as.

$$
S_{\mathrm{w}}^{-1} S_{\mathrm{b}} v=\lambda v
$$

The optimal $v$ is the eigenvector corresponding to the largest eigenvalue of $S_{\mathrm{w}}^{-1} S_{\mathrm{b}}$, or it can be written as.

$$
v=S_{\mathrm{w}}^{-1}\left(m_{1}-m_{2}\right)
$$

provided that $S_{\mathrm{w}}$ is non-singular. The 10-fold crossvalidation was applied for estimation of classification performance.

\section{KNN}

KNN predicts the test sample's category in accordance with the $\mathrm{k}$ training samples that are nearest neighbors to test sample and classifies it based upon largest category probability [54]. Assume there are $j$ training categories as $\left(C_{1}, C_{2}, \ldots, C_{j}\right)$, class $Y$ is the feature vector of all training samples, $E_{i}$ is one of the neighbor in the training set, $X\left(E_{i}, C_{j}\right) \in\{0,1\}$ indicate whether $E_{i}$ belongs to class $C_{j}$, and $\operatorname{Sim}\left(Y, E_{i}\right)$ is the similarity function for feature data $Y$ and $E_{i}$, then the probability density function $P\left(Y, C_{j}\right)$ for $Y$ and $C_{j}$ is given as [54]:

$$
P\left(Y, C_{j}\right)=\sum_{E_{i} \in K N N} \operatorname{Sim}\left(Y, E_{i}\right) \cdot X\left(E_{i}, C_{j}\right)
$$

where, $\operatorname{Sim}\left(Y, E_{i}\right)$ was calculated using the Euclidean distance methods. For closest training data of class, the parameter $\mathrm{k}$ was considered 1 while 10-fold cross-validation was performed for estimation of accuracies.

\section{QDA}

QDA maximizes and minimizes ratio of between-class and within-class variance, provided observations are normally distributed for each class $i$, the ratio test can be performed by [54]:

$$
\frac{f_{i}(X)}{f_{j}(X)}=\frac{\frac{1}{2 \pi\left|\sum_{i}\right|^{1 / 2}} \exp ^{\left[-\frac{1}{2}\left(X-\mu_{i}\right)^{T} \sum_{i}^{-1}\left(X-\mu_{i}\right)\right]}}{\frac{1}{2 \pi\left|\sum_{j}\right|^{1 / 2}} \exp ^{\left[-\frac{1}{2}\left(X-\mu_{j}\right)^{T} \sum_{j}^{-1}\left(X-\mu_{j}\right)\right]}}<t
$$

for some threshold $\mathrm{t}$. Where, $X$ is the feature vector, $\mu_{i}, \mu_{j}$ are the normally distributed mean and $\Sigma_{i}, \Sigma_{j}$ are the covariance matrix of class $i, j$. After rearrangement the separating quadratic surface between classes can be obtained.

$N B$

$\mathrm{NB}$ is considered among commonly used classifiers for classification that is based on probabilistic approach. The model used for NB is as follows [55]:

$$
P(k \mid y)=\frac{P(y \mid k) P(k)}{P(y)}
$$

where $P(k \mid y)$ is the class feature probability for a specified feature, $P(y \mid k)$ is the given class probability of feature, $P(y)$ is the feature prior probability and $P(k)$ is the class prior probability.

\section{Kinematic model of prosthetic leg}

A human leg includes hip, knee and ankle joints. The most efficient joint is the knee, which has to bear the entire body's weight [56]. The knee and hip joints are the key joints used in locomotion; therefore, the proposed model is kept simple by considering only the hip and knee joints for articulation and the ankle joint as fixed. Therefore, only 2 degrees of freedom (DOF) were considered: 1 DOF for the hip joint and 1 for the knee [39, 57-62]. Moreover, the base was assumed fixed, making it two serial-link manipulators in which one manipulator is moved $180^{\circ}$ out of phase with the other one [61-64]. The average thigh clearance given in the literature for a man is $0.78 \mathrm{in}$, and for women, 0.90 in $[65,66]$. The end-effector position and orientation were derived from the Denavit-Hartenberg (DH) notation $[57,59,67,68]$. The front view of the proposed model is shown in Fig. 6, and the leg parameters are listed in Table 1.

\section{Prosthetic leg parameters}

The length parameters of the prosthetic leg are provided in Table 2.

\section{Dynamic model of prosthetic leg}

The dynamics of an n-link robotic leg can be expressed by the following set of $n$ equations [68]

$$
M \ddot{q}+b \dot{q}+g=\tau
$$

where $\mathrm{q}$ is an $\mathrm{n}$-dimensional vector describing the joint positions of the robot, $\tau$ is the vector of input torques, $g$ is the gravitational torque, $b$ represents the Coriolis and centripetal forces caused by the motion of the link, and $M$ is the nxn inertia matrix of the robot.

The coordinates for the hip and knee joints become [69]

$$
x_{1}=x_{a}+r_{1} \sin \theta_{1}
$$




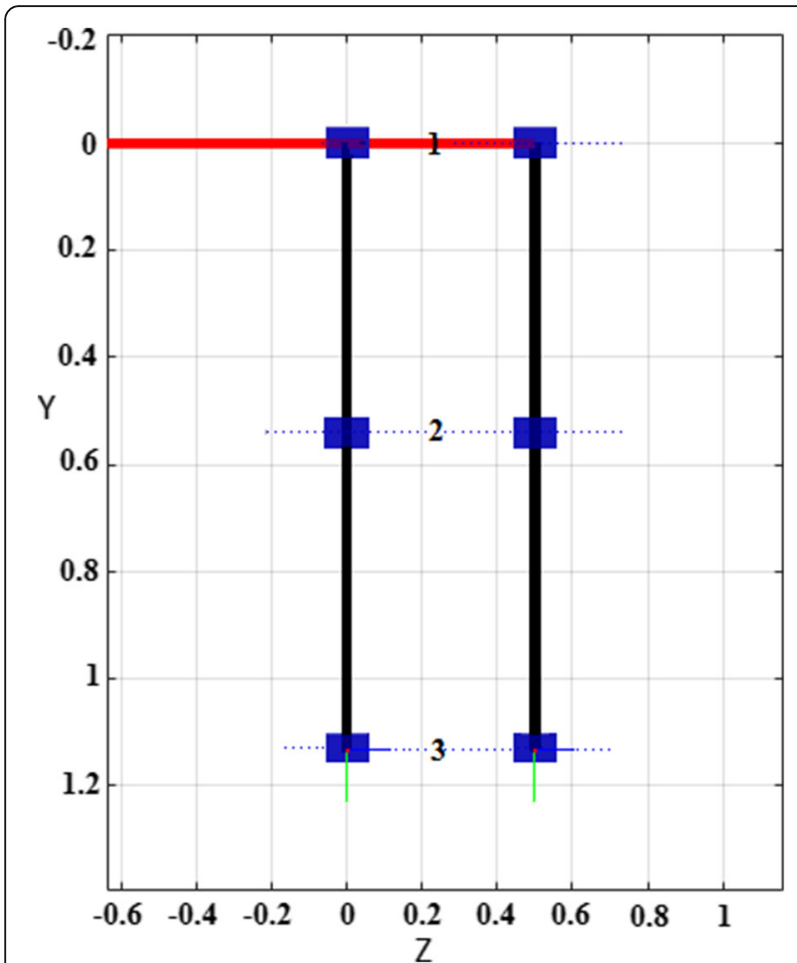

Fig. 6 Front view of biped robot

$$
\begin{aligned}
& y_{1}=y_{a}-r_{1} \cos \theta_{1} \\
& x_{2}=x_{a}+L_{1} \sin \theta_{1}+r_{2} \sin \theta_{2} \\
& y_{2}=y_{a}-L_{1} \cos \theta_{1}-r_{2} \cos \theta_{2}
\end{aligned}
$$

Considering the kinetic and potential energy of the entire system, the Langrangian becomes [69]

$$
\begin{aligned}
\mathrm{L} & =\frac{1}{2} m_{1}\left(\dot{x}_{1}^{2}+\dot{y}_{1}^{2}\right)+\frac{1}{2} I_{1} \dot{\theta}_{1}^{2}+\frac{1}{2} m_{2}\left(\dot{x}_{2}^{2}+\dot{y}_{2}^{2}\right) \\
& +\frac{1}{2} I_{2} \dot{\theta}_{2}^{2}-m_{1} y_{1} g-m_{2} y_{2} g
\end{aligned}
$$

Substituting the joint coordinates and solving the Jacobian matrix, which is the differential relationship between the joint displacements and the end-effecter position, we obtain the hip and knee joint torques $[69,70]$ as

Table 1 Prosthetic-leg D-H notations [68]

\begin{tabular}{lllll}
\hline Link no. & $a_{i-1}$ & $a_{i-1}$ & $d_{i}$ & $\theta_{i}$ \\
\hline 1. & 0 & $\mathrm{~L}_{1}$ & 0 & $\theta_{1}$ \\
2. & 0 & $\mathrm{~L}_{2}$ & 0 & $\theta_{2}$ \\
3. & 0 & $\mathrm{~L}_{3}$ & 0 & $\theta_{3}$ \\
\hline
\end{tabular}

Table 2 Prosthetic leg parameters [95]

\begin{tabular}{lll}
\hline Parameters & Link & Length $(\mathrm{m})$ \\
\hline $\mathrm{L}_{1}$ & Thigh & 0.2 \\
$\mathrm{~L}_{2}$ & Shank & 0.2 \\
$\mathrm{~L}_{3}$ & Pelvic & 0.03 \\
\hline
\end{tabular}

$$
\begin{aligned}
\tau_{1} & =m_{1} r_{1}\left[r_{1} \ddot{\theta}_{1}+\ddot{x}_{a} \cos \theta_{1}+\ddot{y}_{a} \sin \theta_{1}+g \sin \theta_{1}\right] \\
& +m_{2} L_{1}\left[L_{1} \ddot{\theta}_{1}+\ddot{x}_{a} \cos \theta_{1}+\ddot{y}_{a} \sin \theta_{1}+g \sin \theta_{1}\right] \\
& +m_{2} r_{2}\left[-r_{2} \ddot{\theta}_{2}+g \sin \theta_{2}+\ddot{x}_{a} \cos \theta_{2}+\ddot{y}_{a} \sin \theta_{2}\right. \\
& \left.+L_{1}\left(\ddot{\theta}_{1}+\ddot{\theta}_{2}\right) \cos \left(\theta_{1}-\theta_{2}\right)+L_{1}\left(\dot{\theta}_{1}^{2}+\ddot{\theta}_{2}\right) \sin \left(\theta_{1}-\theta_{2}\right)\right] \\
& +I_{2} \ddot{\theta}_{2}+I_{1} \ddot{\theta}_{1}-L_{2} F_{1} \cos \theta_{2}-L_{1} F_{1} \cos \theta_{1}-L_{2} F_{2} \sin \theta_{2}-L_{1} F_{2} \sin \theta_{1}
\end{aligned}
$$

$$
\begin{aligned}
\tau_{2} & =m_{2} r_{2}\left[r_{2} \ddot{\theta}_{2}+\ddot{x}_{a} \cos \theta_{2}+\ddot{y}_{a} \sin \theta_{2}+g \sin \theta_{2}\right. \\
& \left.+L_{1} \ddot{\theta}_{1} \cos \left(\theta_{1}-\theta_{2}\right)-L_{1} \dot{\theta}_{1}^{2} \sin \left(\theta_{1}+\theta_{2}\right)\right] \\
& +I_{2} \ddot{\theta}_{2}-L_{2} F_{1} \cos \theta_{2}-L_{2} F_{2} \sin \theta_{2}
\end{aligned}
$$

\section{Human gait analysis}

The performance parameters of a prosthetic leg can be judged on the basis of how well it mimics the normal human leg. For that purpose, robotic-leg gait patterns can be compared with those of humans taken as a reference. In other words, rehabilitation effectiveness can be measured based on how precisely the amputee can reproduce the kinematics of a healthy person. For modeling purposes, kinematic parameters obtained through gait analysis are necessary.

Uniformity in hip, knee and ankle joint angles has been noted in further analyses of gait cycles at selected walking paces [71, 72]. Fig. 7 represents the mean joint angles for one complete stride. As there is no major variation from person to person, the mean values can be used as a standard for the input joint-angle trajectory $[72,73]$.

\section{Control strategy}

The selected joints torque requires effective control in order to synchronize it with the natural joint-angle trajectory [62, 74-77]. To mimic the natural leg, prosthetic-leg position-error minimization by the proportional derivative computed torque controller (PD-CTC) with gravity compensation has been proposed [40,78].

This is also known as inverse dynamic control, in which the system is cascaded with its inverse to take the overall system gain to unity. Usually, the inverse is incorporated with errors, and so a feedback loop is added for compensation $[40,59,79]$. 


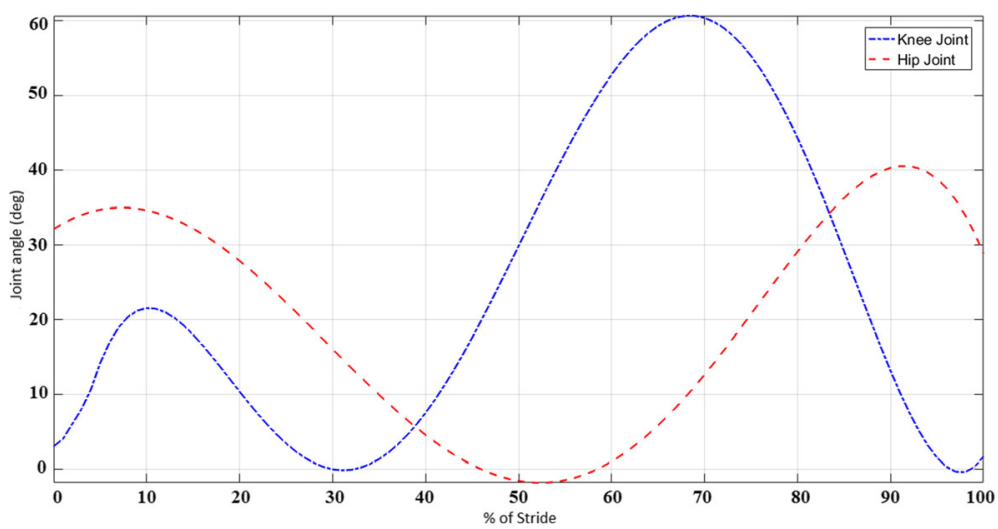

Fig. 7 Joint angles in lower extremities during walking

The computed torque controller (CTC) is given by

$$
\begin{aligned}
Q & =M(q)\left\{K_{v}\left(\ddot{q}^{*}+\dot{q}^{*}+\dot{q}\right)+K_{p}\left(q^{*}-q\right)\right\} \\
& +b(q, \dot{q})+F(\dot{q})+g(q) \\
& =D\left(q, \dot{q},\left(\ddot{q}^{*}+K_{v}\left(\dot{q}^{*}-\dot{q}\right)+K_{p}\left(q^{*}-q\right)\right)\right)
\end{aligned}
$$

where $K_{v}$ and $K_{p}$ are damping matrices or velocity and position gains, and $D($.$) is the inverse dynamics function.$

The inverse dynamics are evaluated at each servo interval. However, the coefficients matrices $M, b$ and $g$ can be evaluated at a lower rate, as the manipulator configuration changes relatively slowly. Assuming ideal parameterization, the error dynamics of the system are modeled as

$$
\ddot{e}+K_{\nu} \dot{e}+K_{p} e=0
$$

where $e=q^{*}-q$. The joint errors are uncoupled; therefore, their dynamics are independent of manipulator configuration.

In the present study, prosthetic leg simulations were performed with different stride lengths given by the $\mathrm{Na}$ tional Center for Health Statistics [65, 66]. Figure 8 shows a simulation plot of the biped robot at different instants.

The complete processing pipeline of entire methodology from signal acquisition to control scheme for minimization of position error is given in Fig. 9. After signal acquisition signals are preprocessed using six filters. Then six statistical features are spatially extracted across 12 channels. Later this data is classified using five different classifiers for comparative analysis of accuracies. Afterwards control
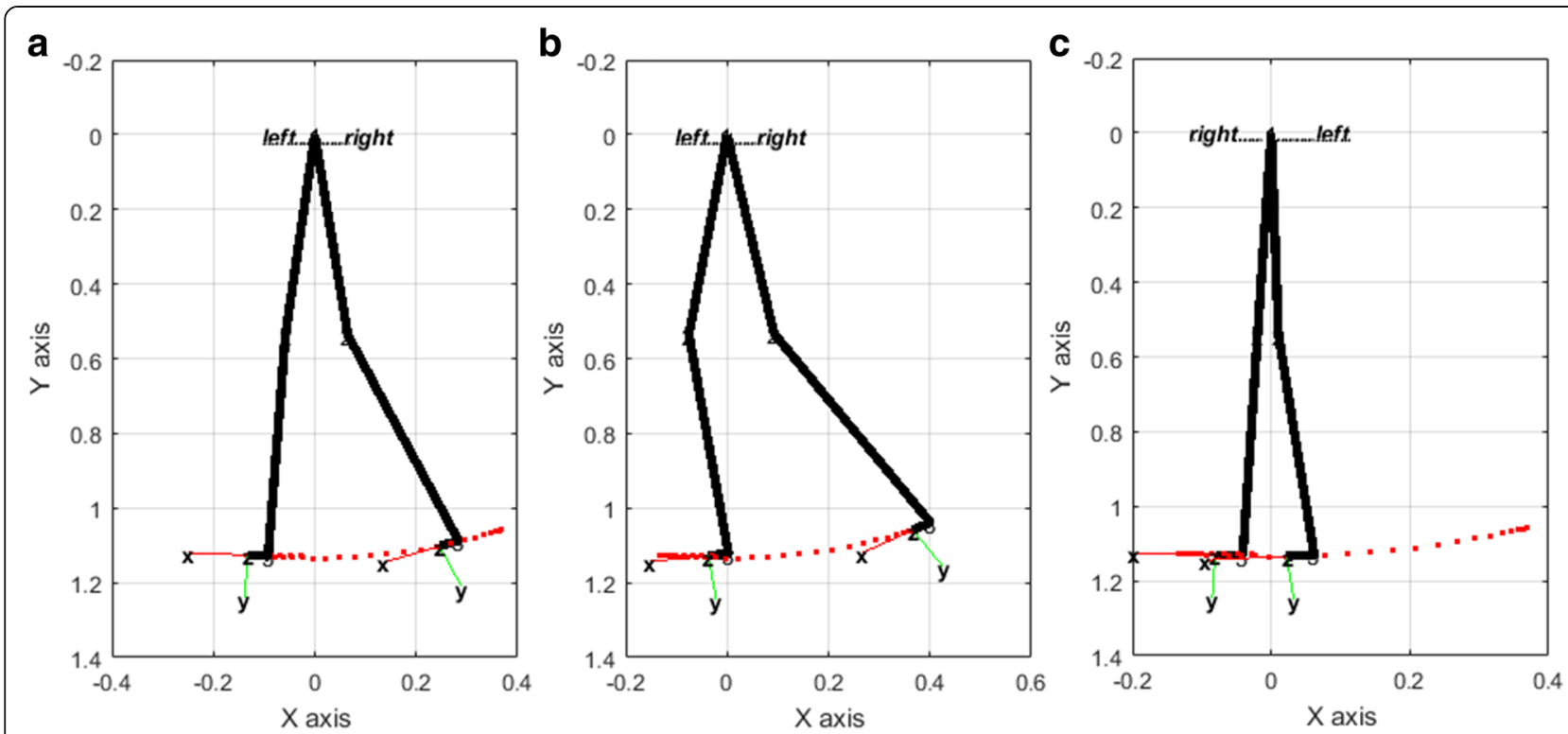

Fig. 8 Side view of biped robot at mid stance (a), terminal stance (b) and mid swing (c) 


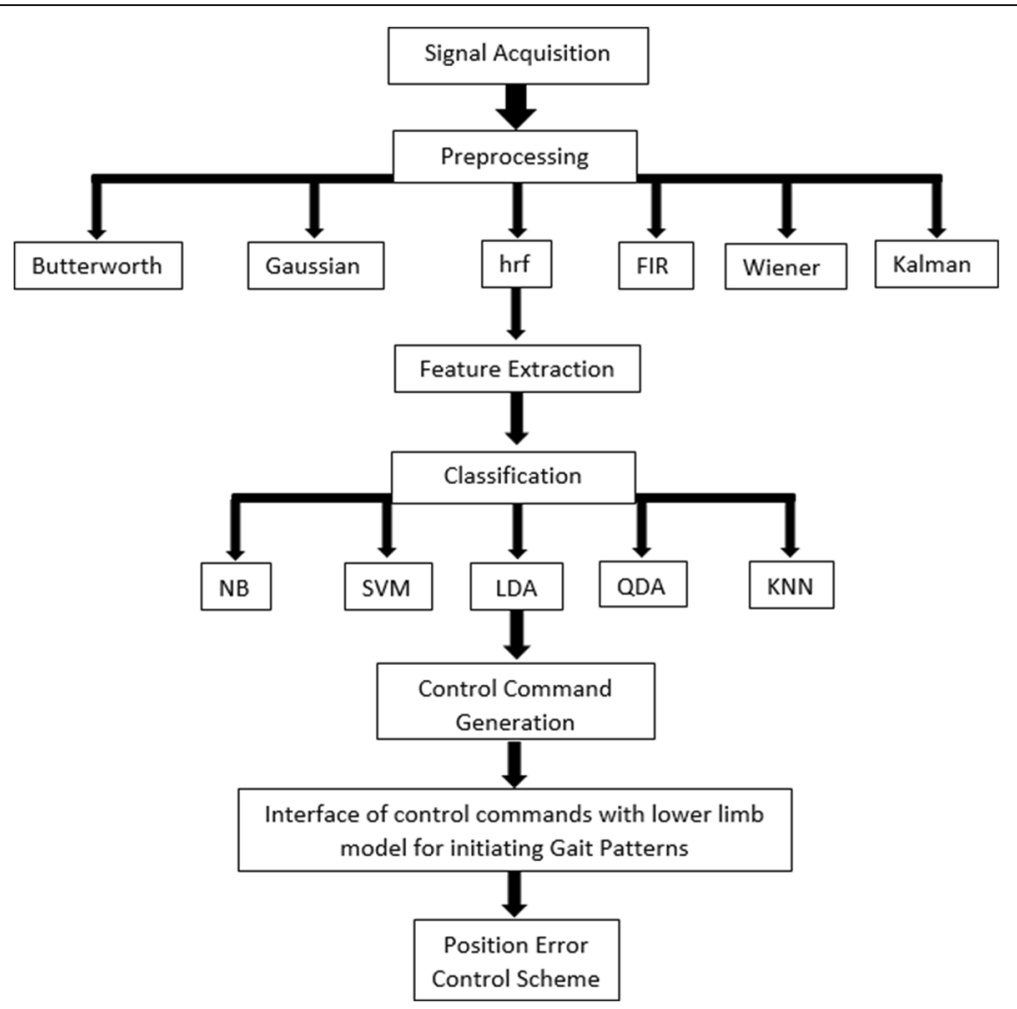

Fig. 9 Processing pipeline of the complete system

commands based on brain intention were generated to move biped robot according to desired gait patterns with minimization of position error.

\section{Results}

As discussed earlier, in order to achieve optimal accuracy, we compared six filters and five classifiers. The classification accuracies were obtained for two-, three- and sixextracted-feature combinations using $\Delta c_{\mathrm{HbO}}(t)$ against all filters and classifiers for the nine subjects. The classification accuracies for the two- and three-feature combinations are shown in Tables 3 and 4, while the six-featurecombination classification accuracies for 6 filters are shown in Table 5. After analyzing Table 5, it was observed that using FIR, Gaussian, Kalman, Wiener and Butterworth processed signals accuracies were below acceptable benchmark for BCI [21]. Moreover, consistent best accuracies were 77.5, 72.5, 68.3, 74.2, 73.3, $80.8,65,76.7$, and $86.7 \%$ for the nine subjects, respectively, as obtained using the SVM classifier with hrf processed signals. The statistically significant $p$-values of the classifiers for the $\mathrm{HbO}$ signals shown in Table 6 verify the greater statistical significance of the SVM over all of the other above-noted classifiers. The confidence interval was adjusted to 0.01 after applying Bonferroni correction of multiple comparisons. The results also demonstrate the significant effect of selection of filtering technique on classification accuracies. The below acceptable benchmark accuracies obtained using FIR, Butterworth, Kalman, Gaussian and Wiener filters, for this specific task, does not imply their futility for BCI studies. These filters have been shown to work well for several other tasks, for example, motor imagery, mental arithmetic etc. in previous studies [20, 23, 29, 47, 55, 80-84].

\section{Online $\mathrm{BCI}$}

In online $\mathrm{BCI}$, we require minimum computation so as to reduce execution delay for control-command generation. Most of the previous fNIRS-BCI studies have used LDA for online classification, because it provides a balance between time of execution and classification accuracy [23]. Thus, in our study, we used LDA with six-feature combinations. For real-time BCI, we divided the total of 10 trials into two sections: one section of 9 training trials and the other of 1 testing trial. The classifier was first trained offline using 9 trials having 10 runs with ten-fold cross-validation. The onetime-trained classifier was then used to classify the one unknown testing trial in online BCI. To avoid a false trigger of a control command, the testing trial was randomly divided into 10 indices having observations approximately equal to 10 disjoint subsets. Each subset was then classified to make a binary decision. Based on 
Table 3 Classification accuracies of 9-subjects across 6-filters using 2-feature combination for 6-classifiers

\begin{tabular}{|c|c|c|c|c|c|c|c|c|c|c|c|c|c|c|c|}
\hline \multirow[t]{3}{*}{ Feature } & \multicolumn{15}{|c|}{ Accuracy (\%) } \\
\hline & \multicolumn{5}{|c|}{$\mathrm{S} 1 / \mathrm{S} 2 / \mathrm{S} 3$} & \multicolumn{5}{|c|}{ S4/S5/S6 } & \multicolumn{5}{|c|}{ S7/S8/S9 } \\
\hline & KNN & LDA & QDA & NB & SVM & KNN & LDA & QDA & NB & SVM & KNN & LDA & QDA & NB & SVM \\
\hline SP, SK & 56.7 & 49.2 & 51.7 & 62.5 & 41.7 & 64.6 & 56.3 & 62.1 & 64.6 & 62.5 & 60.4 & 60.4 & 69.2 & 66.3 & 58.3 \\
\hline SM, SK & 57.5 & 52.1 & 57.1 & 62.9 & 59.2 & 62.5 & 66.3 & 62.1 & 66.3 & 65.0 & 60.4 & 60.8 & 60.8 & 63.8 & 61.7 \\
\hline SS, SK & 57.1 & 51.7 & 62.9 & 66.7 & 66.7 & 60.8 & 57.9 & 59.2 & 61.3 & 52.5 & 60.8 & 57.9 & 60.0 & 62.5 & 57.5 \\
\hline $\mathrm{KR}, \mathrm{SK}$ & 57.9 & 54.6 & 41.3 & 62.1 & 55.0 & 63.3 & 61.7 & 57.9 & 62.5 & 63.3 & 67.1 & 60.4 & 60.4 & 61.7 & 52.5 \\
\hline VR, SK & 57.1 & 48.3 & 50.0 & 62.5 & 47.5 & 60.0 & 53.3 & 63.3 & 67.5 & 62.5 & 60.8 & 61.3 & 67.9 & 65.0 & 63.3 \\
\hline $\mathrm{SP}, \mathrm{KR}$ & 52.1 & 45.4 & 54.2 & 62.1 & 54.2 & 54.2 & 66.3 & 60.0 & 62.5 & 74.2 & 65.0 & 58.3 & 61.3 & 64.2 & 60.0 \\
\hline$S M, K R$ & 52.5 & 57.1 & 62.1 & 63.8 & 59.2 & 54.6 & 68.3 & 63.3 & 63.3 & 70.8 & 65.0 & 58.8 & 59.2 & 63.8 & 55.0 \\
\hline $\mathrm{SS}, \mathrm{KR}$ & 52.9 & 54.6 & 65.8 & 67.5 & 68.3 & 55.4 & 63.3 & 55.4 & 64.2 & 68.3 & 65.0 & 58.3 & 63.3 & 62.9 & 59.2 \\
\hline$V R, K R$ & 52.9 & 42.5 & 47.1 & 62.1 & 53.3 & 55.8 & 62.5 & 63.8 & 67.5 & 74.2 & 65.0 & 65.4 & 62.5 & 64.6 & 65.0 \\
\hline SM, SP & 57.9 & 52.1 & 59.2 & 62.5 & 51.7 & 63.8 & 64.2 & 59.2 & 62.9 & 72.5 & 57.9 & 60.4 & 60.0 & 62.9 & 57.5 \\
\hline$S M, V R$ & 61.3 & 51.7 & 54.2 & 61.3 & 55.8 & 61.3 & 60.8 & 63.8 & 69.6 & 71.7 & 57.1 & 60.0 & 59.2 & 65.0 & 60.0 \\
\hline SS, SP & 60.0 & 55.4 & 67.9 & 66.7 & 70.0 & 65.0 & 43.3 & 56.3 & 60.4 & 62.5 & 58.8 & 61.7 & 62.9 & 65.0 & 58.3 \\
\hline SS, VR & 57.1 & 52.9 & 63.3 & 66.3 & 72.5 & 62.9 & 40.8 & 63.8 & 70.4 & 65.8 & 62.1 & 65.4 & 64.2 & 64.6 & 60.0 \\
\hline VR, SP & 52.5 & 51.3 & 51.7 & 62.5 & 40.0 & 59.2 & 50.0 & 61.3 & 63.3 & 67.5 & 49.6 & 60.8 & 67.1 & 65.0 & 62.5 \\
\hline SM, SS & 61.3 & 54.6 & 64.6 & 68.3 & 66.7 & 72.5 & 56.7 & 53.8 & 59.2 & 61.7 & 58.8 & 60.8 & 59.6 & 63.3 & 60.0 \\
\hline SP, SK & 58.3 & 51.7 & 62.5 & 63.3 & 59.2 & 54.2 & 47.9 & 52.1 & 63.8 & 65.0 & 52.5 & 43.3 & 40.8 & 60.8 & 48.3 \\
\hline SM, SK & 58.3 & 55.4 & 64.2 & 67.1 & 69.2 & 56.3 & 45.4 & 56.3 & 64.2 & 60.8 & 50.0 & 50.8 & 46.3 & 59.2 & 61.7 \\
\hline SS, SK & 57.9 & 64.2 & 55.4 & 68.3 & 70.8 & 57.1 & 62.5 & 58.8 & 62.5 & 64.2 & 51.3 & 66.3 & 65.8 & 62.9 & 70.0 \\
\hline KR, SK & 67.1 & 63.3 & 71.3 & 62.9 & 67.5 & 60.0 & 57.1 & 57.1 & 61.7 & 55.8 & 51.3 & 57.1 & 58.3 & 62.1 & 59.2 \\
\hline VR, SK & 57.9 & 51.3 & 61.3 & 63.8 & 60.8 & 56.7 & 50.4 & 55.4 & 60.0 & 63.3 & 51.7 & 54.6 & 58.8 & 62.1 & 65.0 \\
\hline $\mathrm{SP}, \mathrm{KR}$ & 55.4 & 53.3 & 62.9 & 62.5 & 57.5 & 55.0 & 50.4 & 56.7 & 62.1 & 55.8 & 52.1 & 55.0 & 59.2 & 60.8 & 59.2 \\
\hline$S M, K R$ & 54.2 & 57.5 & 62.9 & 68.3 & 65.8 & 55.0 & 51.7 & 59.6 & 60.0 & 63.3 & 52.1 & 56.3 & 56.7 & 60.8 & 58.3 \\
\hline $\mathrm{SS}, \mathrm{KR}$ & 54.2 & 62.1 & 48.8 & 63.3 & 65.8 & 53.3 & 59.6 & 65.0 & 60.4 & 69.2 & 52.9 & 71.3 & 68.3 & 62.1 & 68.3 \\
\hline$V R, K R$ & 54.2 & 43.8 & 51.7 & 61.3 & 53.3 & 52.9 & 56.3 & 51.3 & 60.8 & 59.2 & 52.9 & 56.7 & 62.9 & 62.1 & 65.0 \\
\hline SM, SP & 67.9 & 56.7 & 72.9 & 64.6 & 66.7 & 64.2 & 42.9 & 58.8 & 63.3 & 61.7 & 60.8 & 47.9 & 59.6 & 59.2 & 53.3 \\
\hline$S M, V R$ & 65.8 & 55.8 & 72.1 & 65.0 & 68.3 & 59.6 & 44.6 & 64.2 & 61.7 & 65.8 & 55.4 & 47.9 & 62.1 & 62.9 & 65.0 \\
\hline SS, SP & 53.8 & 62.1 & 56.7 & 64.2 & 61.7 & 69.2 & 57.9 & 59.2 & 64.6 & 63.3 & 66.7 & 67.5 & 67.9 & 62.5 & 62.5 \\
\hline SS, VR & 59.6 & 61.7 & 55.4 & 62.9 & 61.7 & 57.5 & 62.1 & 60.8 & 63.3 & 64.2 & 59.6 & 66.3 & 67.1 & 64.6 & 65.0 \\
\hline VR, SP & 49.2 & 55.0 & 64.6 & 62.1 & 59.2 & 59.6 & 53.3 & 60.8 & 60.8 & 62.5 & 54.6 & 55.0 & 65.0 & 62.9 & 69.2 \\
\hline SM, SS & 60.8 & 62.9 & 63.8 & 66.7 & 65.8 & 75.0 & 58.3 & 59.2 & 67.1 & 67.5 & 75.0 & 68.3 & 68.8 & 63.3 & 75.8 \\
\hline SP, SK & 59.6 & 58.8 & 59.6 & 61.3 & 59.2 & 47.1 & 57.5 & 55.8 & 55.8 & 52.5 & 64.2 & 63.8 & 71.3 & 70.4 & 76.7 \\
\hline SM, SK & 59.6 & 62.1 & 62.9 & 64.6 & 59.2 & 47.5 & 53.8 & 51.7 & 57.9 & 50.8 & 65.8 & 65.8 & 72.5 & 72.9 & 76.7 \\
\hline SS, SK & 59.6 & 56.7 & 59.6 & 63.8 & 63.3 & 47.5 & 55.4 & 57.1 & 63.8 & 63.3 & 65.8 & 67.1 & 73.8 & 75.8 & 80.0 \\
\hline KR, SK & 62.1 & 48.3 & 49.6 & 62.5 & 51.7 & 54.2 & 52.5 & 46.3 & 62.5 & 50.0 & 77.5 & 67.5 & 65.8 & 72.1 & 78.3 \\
\hline VR, SK & 59.6 & 59.6 & 57.1 & 60.0 & 60.8 & 47.5 & 60.8 & 58.8 & 62.9 & 55.8 & 65.8 & 63.8 & 75.0 & 70.4 & 75.8 \\
\hline $\mathrm{SP}, \mathrm{KR}$ & 56.7 & 39.6 & 54.2 & 62.5 & 56.7 & 57.9 & 58.8 & 57.9 & 59.2 & 56.7 & 71.3 & 67.5 & 74.2 & 69.2 & 74.2 \\
\hline$S M, K R$ & 55.8 & 43.8 & 60.4 & 60.0 & 58.3 & 58.8 & 53.3 & 53.8 & 62.5 & 55.8 & 71.3 & 66.3 & 74.2 & 72.9 & 80.0 \\
\hline $\mathrm{SS}, \mathrm{KR}$ & 55.4 & 44.2 & 49.2 & 62.5 & 50.0 & 58.3 & 56.3 & 63.8 & 65.0 & 62.5 & 71.3 & 71.7 & 73.8 & 71.3 & 79.2 \\
\hline$V R, K R$ & 55.4 & 50.8 & 47.5 & 51.7 & 50.8 & 58.3 & 60.8 & 65.4 & 62.9 & 54.2 & 71.3 & 66.7 & 73.8 & 68.8 & 72.5 \\
\hline SM, SP & 57.1 & 38.3 & 57.1 & 58.3 & 57.5 & 57.1 & 55.8 & 57.1 & 59.6 & 53.3 & 73.8 & 59.6 & 67.5 & 62.1 & 70.8 \\
\hline$S M, V R$ & 64.2 & 49.2 & 63.8 & 56.7 & 57.5 & 60.4 & 58.8 & 60.0 & 64.6 & 57.5 & 61.7 & 56.3 & 63.8 & 62.1 & 70.8 \\
\hline
\end{tabular}


Table 3 Classification accuracies of 9-subjects across 6-filters using 2-feature combination for 6-classifiers (Continued)

\begin{tabular}{|c|c|c|c|c|c|c|c|c|c|c|c|c|c|c|c|}
\hline \multirow[t]{3}{*}{ Feature } & \multicolumn{15}{|c|}{ Accuracy (\%) } \\
\hline & \multicolumn{5}{|c|}{$51 / S 2 / S 3$} & \multicolumn{5}{|c|}{ S4/S5/S6 } & \multicolumn{5}{|c|}{ S7/S8/S9 } \\
\hline & KNN & LDA & QDA & NB & SVM & KNN & LDA & QDA & NB & SVM & KNN & LDA & QDA & NB & SVM \\
\hline SS, SP & 52.5 & 41.7 & 47.9 & 61.3 & 57.5 & 65.8 & 62.1 & 63.3 & 65.8 & 63.3 & 66.3 & 60.4 & 72.5 & 70.8 & 74.2 \\
\hline SS, VR & 62.5 & 52.1 & 54.2 & 52.5 & 55.8 & 65.4 & 63.8 & 62.1 & 65.8 & 70.8 & 66.3 & 57.9 & 68.8 & 73.3 & 70.0 \\
\hline$V R, S P$ & 54.6 & 57.5 & 55.0 & 48.3 & 57.5 & 53.3 & 62.5 & 65.0 & 62.5 & 52.5 & 57.9 & 62.9 & 74.6 & 65.4 & 75.8 \\
\hline SM, SS & 66.7 & 47.5 & 61.3 & 58.3 & 57.5 & 73.8 & 57.1 & 54.6 & 65.0 & 63.3 & 77.5 & 60.4 & 77.1 & 78.8 & 85.8 \\
\hline
\end{tabular}

the ten-fold classified data, an average threshold of "90\% true" was set for accurate triggering.

\section{Error plots}

The trigger command generated based on brain intention is used to generate gait cycles of a prosthetic leg through given human joint-angle trajectories, while the PD-CTC controller minimizes joint angle and position error. Joint-angle and position-error plots for reference input trajectories of the left and right leg are provided in Figs. 10 and 11, respectively.

Figure 12 provides a brain intention versus joint-angle plot. When the rest intention is transmitted, the prosthetic leg retains its previous joint angles while updating the next input joint angles for the walk intention.

\section{Discussion}

In past studies, researchers have endeavored to improve classification accuracies by using different feature combinations or by making changes to machinelearning algorithms. The frequently used features are signal mean (SM) $[20,29,48,83,85-88]$, signal slope (SS) [20, 29, 52, 83, 89], signal variance (SV) [52, 86], slope kurtosis (KR) [86], signal peak (SP) [52, 86, 90] and signal skewness (SK) $[52,86]$. To avoid false triggers in rehabilitation, the consistently best accuracies achieved using six-dimensional feature combinations have been considered compulsory, as reported in [55]; however, in the present study, for the 2-feature combination SM/SS, the best average accuracy, 67\%, was achieved, while for the three-feature combination SM/ SP/SS, an optimal average accuracy of $71 \%$ was obtained. Similar 2-feature combinations have been reported for two-class imagery movement by Naseer et al. [29], who, using time windows of SS and SM for right- and left-wrist motor imageries, increased accuracies from 83 to $87.28 \%$. Due to individual-participant differences, these classification accuracies varied. The differences might have been due to scalp-cortex distance and head shape, both of which can cause major variation, as reported in [29]. The low classification accuracies might have been due to the fact that the hemodynamic responses of people with motor impairment due to tetraplegia or multiple sclerosis differ as compared with healthy persons, as discussed in [91]. Moreover, an optimal classifier also plays a vital role in enhancing performance accuracies, as reported in [55], where five classifiers were compared to obtain the maximum accuracy. For the present study, the proposed classifiers were LDA and SVM, as also reported in $[23,48,49,53,55$, 92].

For an online interface, we proposed a novel methodology in which the testing trial is divided into 10 indices and each subsection is separately classified. The triggering command was generated based on a 90\% average true benchmark of classified subsections. A similar realtime interface was reported in [23], but it used a separate framework for binary decoding. Furthermore, for a normal walk task reported in [22] based on the use of an online interface, a separate methodology also was used, in that case to synchronize the triggers of fNIRS signals and the gait system.

In the second part of this study a proposed nonlinear position control for a prosthetic leg was studied for gait-rehabilitation purposes. An independent, selfsufficient mechanism was developed that can mimic the normal human gait pattern based on PD-CTC. It is evident from Fig. 9 that the controller minimized the position error in less than $2.5 \mathrm{~s}$. The same strategy was seen in [33], which minimized joint error using a sliding-mode control, but a steady-state error was observed. Similarly, when adaptive control was applied in a previous study [32], a constant error was seen across hip movement in the reported results. Moreover, consistent error was observed across knee and ankle angles in [77], which reported that error increases with increaing torque bounds.

fNIRS is an indirect optical measurement technique that measures hemodynamic changes instead of neural activity. Accordingly, there is always a delay between an activity performed and a detected response; thus, in such decoding tasks, classification accuracy is compromised. With advanced filtering techniques [11, 93, 94], different feature combinations [81] and various classification techniques $[55,80]$, accuracies can be increased. One additional limitation of this study is that it generates the control command based on the walk intention whereas during the rest intention it holds the lower limb to its 
Table 4 Classification accuracies of 9-subjects across 6-filters using 3-feature combination for 6-classifiers

\begin{tabular}{|c|c|c|c|c|c|c|c|c|c|c|c|c|c|c|c|}
\hline \multirow[t]{3}{*}{ Feature } & \multicolumn{15}{|c|}{ Accuracy (\%) } \\
\hline & \multicolumn{5}{|c|}{ S1/S2/S3 } & \multicolumn{5}{|c|}{ S4/S5/S6 } & \multicolumn{5}{|c|}{$57 / 58 / S 9$} \\
\hline & $\overline{\mathrm{KNN}}$ & LDA & QDA & NB & $\overline{\text { SVM }}$ & $\overline{\mathrm{KNN}}$ & LDA & QDA & NB & $\overline{\text { SVM }}$ & $\mathrm{KNN}$ & LDA & QDA & NB & SVM \\
\hline SM, SP, SS & 60.4 & 58.8 & 71.7 & 67.5 & 74.2 & 70.8 & 63.8 & 58.3 & 63.3 & 73.3 & 58.8 & 61.7 & 65.8 & 63.3 & 60.0 \\
\hline $\mathrm{SM}, \mathrm{SP}, \mathrm{KR}$ & 52.5 & 52.9 & 60.0 & 62.1 & 65.8 & 54.2 & 68.8 & 64.2 & 63.3 & 75.0 & 65.0 & 58.8 & 59.2 & 65.4 & 51.7 \\
\hline SM, SP, SK & 56.7 & 54.6 & 55.4 & 61.3 & 58.3 & 64.6 & 65.8 & 63.8 & 62.1 & 69.2 & 60.4 & 59.2 & 63.8 & 62.9 & 60.8 \\
\hline$S M, S P, V R$ & 57.9 & 50.0 & 57.1 & 57.5 & 60.8 & 63.8 & 66.7 & 66.3 & 65.8 & 73.3 & 57.9 & 59.6 & 62.5 & 62.9 & 56.7 \\
\hline SS, SP, SK & 56.7 & 55.4 & 57.5 & 66.7 & 75.0 & 64.6 & 55.8 & 62.9 & 64.6 & 64.2 & 60.4 & 62.1 & 63.3 & 67.1 & 64.2 \\
\hline$S P, K R, V R$ & 52.1 & 52.5 & 56.7 & 60.4 & 55.8 & 54.2 & 67.1 & 62.9 & 66.3 & 75.8 & 65.0 & 64.6 & 66.7 & 67.5 & 63.3 \\
\hline$S P, S S, V R$ & 60.0 & 55.8 & 61.3 & 66.3 & 72.5 & 65.0 & 44.6 & 58.3 & 64.6 & 71.7 & 58.8 & 60.4 & 66.3 & 64.2 & 57.5 \\
\hline $\mathrm{VR}, \mathrm{SS}, \mathrm{KR}$ & 52.9 & 50.4 & 60.8 & 67.5 & 69.2 & 55.4 & 62.1 & 60.4 & 66.3 & 77.5 & 65.0 & 64.6 & 65.0 & 66.7 & 63.3 \\
\hline VR, SS, SM & 61.7 & 60.8 & 69.2 & 66.3 & 73.3 & 72.5 & 58.3 & 64.6 & 70.0 & 71.7 & 58.8 & 62.9 & 60.8 & 64.6 & 62.5 \\
\hline VR, SM, SK & 57.5 & 53.3 & 54.2 & 56.7 & 60.0 & 62.5 & 65.8 & 66.7 & 67.5 & 68.3 & 60.4 & 57.9 & 67.5 & 65.4 & 61.7 \\
\hline $\mathrm{VR}, \mathrm{SM}, \mathrm{KR}$ & 52.5 & 52.5 & 56.3 & 58.8 & 60.8 & 54.6 & 67.5 & 67.1 & 70.0 & 80.0 & 65.0 & 60.8 & 62.9 & 67.1 & 57.5 \\
\hline $\mathrm{KR}, \mathrm{SP}, \mathrm{SS}$ & 52.1 & 54.2 & 65.0 & 67.5 & 68.3 & 54.2 & 65.8 & 59.6 & 62.5 & 73.3 & 65.0 & 61.3 & 63.3 & 63.3 & 61.7 \\
\hline $\mathrm{KR}, \mathrm{SM}, \mathrm{SK}$ & 57.9 & 52.1 & 59.6 & 61.7 & 65.0 & 63.3 & 67.9 & 63.3 & 64.2 & 69.2 & 67.1 & 63.3 & 59.2 & 62.5 & 55.0 \\
\hline SS, SM, SK & 57.5 & 55.4 & 64.6 & 68.3 & 67.5 & 63.3 & 65.8 & 61.3 & 65.0 & 63.3 & 60.4 & 59.6 & 61.7 & 63.3 & 60.8 \\
\hline SS, SK, KR & 57.9 & 56.7 & 48.8 & 66.7 & 73.3 & 63.3 & 61.3 & 57.5 & 62.5 & 70.0 & 67.1 & 58.8 & 64.2 & 59.6 & 56.7 \\
\hline $\mathrm{SS}, \mathrm{SM}, \mathrm{KR}$ & 52.5 & 55.8 & 68.8 & 67.1 & 68.3 & 54.6 & 68.3 & 63.8 & 64.2 & 67.5 & 65.0 & 64.6 & 65.4 & 66.3 & 59.2 \\
\hline SS, SK, VR & 57.1 & 55.8 & 54.6 & 68.3 & 75.0 & 60.8 & 54.2 & 62.1 & 68.8 & 62.5 & 60.8 & 63.3 & 66.3 & 65.0 & 69.2 \\
\hline SK, VR, KR & 57.9 & 51.3 & 47.1 & 60.0 & 49.2 & 63.3 & 62.1 & 58.8 & 64.6 & 68.3 & 67.1 & 64.2 & 65.0 & 64.6 & 68.3 \\
\hline SK, SP, KR & 57.9 & 50.8 & 46.7 & 61.3 & 48.3 & 63.3 & 67.1 & 62.1 & 62.1 & 71.7 & 67.1 & 60.4 & 65.4 & 63.3 & 55.8 \\
\hline SK, VR, SP & 56.7 & 50.8 & 54.2 & 55.8 & 45.8 & 64.6 & 56.7 & 62.5 & 67.9 & 70.8 & 60.4 & 62.1 & 64.2 & 67.1 & 59.2 \\
\hline$S M, S P, S S$ & 70.4 & 57.5 & 73.8 & 65.4 & 74.2 & 81.3 & 57.9 & 60.4 & 62.9 & 70.8 & 73.3 & 67.5 & 70.8 & 61.7 & 72.5 \\
\hline $\mathrm{SM}, \mathrm{SP}, \mathrm{KR}$ & 55.8 & 55.0 & 70.8 & 65.8 & 71.7 & 56.7 & 50.8 & 65.8 & 62.1 & 63.3 & 53.3 & 60.0 & 59.6 & 59.2 & 64.2 \\
\hline SM, SP, SK & 58.3 & 53.8 & 70.0 & 66.3 & 70.0 & 54.2 & 44.2 & 61.3 & 62.5 & 62.5 & 51.3 & 48.3 & 53.8 & 57.9 & 50.8 \\
\hline$S M, S P, V R$ & 67.9 & 54.2 & 72.5 & 62.1 & 76.7 & 64.2 & 47.1 & 62.9 & 60.0 & 65.0 & 60.8 & 54.6 & 58.8 & 61.3 & 66.7 \\
\hline SS, SP, SK & 58.3 & 62.1 & 56.3 & 67.9 & 70.0 & 54.2 & 59.2 & 59.2 & 62.5 & 65.8 & 52.5 & 65.4 & 65.0 & 60.8 & 72.5 \\
\hline$S P, K R, V R$ & 55.4 & 54.2 & 62.5 & 60.8 & 60.0 & 55.0 & 53.3 & 57.1 & 60.4 & 55.8 & 52.1 & 57.9 & 62.5 & 61.7 & 62.5 \\
\hline $\mathrm{SP}, \mathrm{SS}, \mathrm{VR}$ & 53.8 & 60.0 & 62.9 & 65.0 & 69.2 & 69.2 & 57.9 & 63.8 & 64.6 & 63.3 & 66.7 & 69.2 & 70.8 & 62.5 & 70.0 \\
\hline VR, SS, KR & 54.2 & 60.8 & 50.0 & 65.8 & 64.2 & 53.3 & 59.2 & 58.8 & 61.3 & 68.3 & 52.9 & 72.5 & 68.8 & 65.4 & 67.5 \\
\hline VR, SS, SM & 61.7 & 57.9 & 69.6 & 64.6 & 72.5 & 75.0 & 59.6 & 65.4 & 65.0 & 73.3 & 75.0 & 67.1 & 72.5 & 63.3 & 69.2 \\
\hline VR, SM, SK & 58.3 & 54.6 & 70.4 & 65.4 & 71.7 & 56.3 & 46.3 & 62.5 & 60.0 & 65.8 & 50.0 & 49.6 & 60.8 & 60.8 & 65.8 \\
\hline $\mathrm{VR}, \mathrm{SM}, \mathrm{KR}$ & 54.2 & 53.8 & 72.1 & 66.3 & 68.3 & 55.0 & 54.6 & 66.7 & 58.3 & 66.7 & 52.1 & 59.2 & 65.0 & 61.3 & 68.3 \\
\hline $\mathrm{KR}, \mathrm{SP}, \mathrm{SS}$ & 55.4 & 60.8 & 51.3 & 63.8 & 64.2 & 54.6 & 55.4 & 57.9 & 62.9 & 68.3 & 52.1 & 70.4 & 70.0 & 60.4 & 70.8 \\
\hline $\mathrm{KR}, \mathrm{SM}, \mathrm{SK}$ & 67.1 & 62.9 & 75.0 & 66.3 & 70.8 & 60.0 & 53.3 & 57.1 & 61.3 & 57.5 & 51.3 & 55.0 & 54.6 & 60.4 & 60.8 \\
\hline SS, SM, SK & 58.3 & 62.1 & 63.8 & 70.0 & 70.0 & 56.3 & 59.6 & 59.2 & 64.2 & 67.5 & 50.0 & 68.3 & 70.0 & 62.9 & 73.3 \\
\hline SS, SK, KR & 67.1 & 61.7 & 66.7 & 69.2 & 76.7 & 60.0 & 59.6 & 63.8 & 58.8 & 68.3 & 51.3 & 72.5 & 70.0 & 62.5 & 69.2 \\
\hline $\mathrm{SS}, \mathrm{SM}, \mathrm{KR}$ & 54.2 & 60.0 & 59.2 & 65.8 & 70.0 & 55.0 & 59.2 & 63.8 & 61.3 & 70.8 & 52.1 & 69.2 & 71.7 & 63.8 & 78.3 \\
\hline SS, SK, VR & 57.9 & 62.1 & 56.3 & 69.2 & 72.5 & 57.1 & 62.9 & 59.6 & 61.3 & 68.3 & 51.3 & 66.3 & 65.0 & 64.2 & 62.5 \\
\hline$S K, V R, K R$ & 67.1 & 57.1 & 73.3 & 62.9 & 68.3 & 60.0 & 55.4 & 56.7 & 59.6 & 60.0 & 51.3 & 54.2 & 61.3 & 62.1 & 67.5 \\
\hline SK, SP, KR & 67.1 & 58.8 & 74.6 & 62.5 & 70.0 & 60.0 & 50.0 & 54.2 & 61.7 & 55.0 & 51.7 & 55.4 & 57.9 & 61.3 & 53.3 \\
\hline$S K, V R, S P$ & 58.3 & 51.7 & 56.7 & 60.4 & 59.2 & 54.2 & 53.3 & 61.7 & 61.3 & 61.7 & 52.5 & 51.3 & 61.7 & 61.3 & 60.8 \\
\hline SM, SP, SS & 61.7 & 43.8 & 57.1 & 55.8 & 55.8 & 68.8 & 60.4 & 71.7 & 62.5 & 75.0 & 80.4 & 60.8 & 76.3 & 76.3 & 83.3 \\
\hline $\mathrm{SM}, \mathrm{SP}, \mathrm{KR}$ & 56.7 & 38.8 & 56.3 & 56.7 & 61.7 & 57.5 & 56.3 & 57.9 & 56.3 & 55.0 & 71.3 & 65.4 & 65.4 & 74.6 & 80.0 \\
\hline SM, SP, SK & 59.6 & 60.4 & 64.2 & 59.6 & 60.0 & 47.1 & 57.1 & 58.3 & 57.1 & 54.2 & 64.2 & 62.5 & 66.7 & 72.9 & 81.7 \\
\hline
\end{tabular}


Table 4 Classification accuracies of 9-subjects across 6-filters using 3-feature combination for 6-classifiers (Continued)

\begin{tabular}{|c|c|c|c|c|c|c|c|c|c|c|c|c|c|c|c|}
\hline \multirow[t]{3}{*}{ Feature } & \multicolumn{15}{|c|}{ Accuracy (\%) } \\
\hline & \multicolumn{5}{|c|}{ S1/S2/S3 } & \multicolumn{5}{|c|}{ S4/S5/S6 } & \multicolumn{5}{|c|}{$57 / 58 / 59$} \\
\hline & KNN & LDA & QDA & NB & SVM & KNN & LDA & QDA & NB & SVM & KNN & LDA & QDA & NB & SVM \\
\hline $\mathrm{SM}, \mathrm{SP}, \mathrm{VR}$ & 57.1 & 62.9 & 64.2 & 55.0 & 58.3 & 57.1 & 62.1 & 64.6 & 62.1 & 53.3 & 73.8 & 62.9 & 63.8 & 63.8 & 77.5 \\
\hline SS, SP, SK & 59.6 & 60.4 & 59.6 & 60.4 & 58.3 & 47.1 & 63.8 & 64.6 & 64.6 & 63.3 & 64.2 & 63.8 & 73.3 & 76.3 & 79.2 \\
\hline$S P, K R, V R$ & 56.7 & 56.3 & 56.3 & 49.6 & 59.2 & 57.9 & 62.9 & 65.0 & 62.1 & 53.3 & 71.3 & 65.8 & 69.6 & 67.9 & 77.5 \\
\hline $\mathrm{SP}, \mathrm{SS}, \mathrm{VR}$ & 52.5 & 57.1 & 55.4 & 47.5 & 55.0 & 65.8 & 64.6 & 67.9 & 63.8 & 65.0 & 66.3 & 62.5 & 76.3 & 72.5 & 82.5 \\
\hline $\mathrm{VR}, \mathrm{SS}, \mathrm{KR}$ & 55.4 & 56.7 & 53.8 & 51.3 & 58.3 & 58.3 & 62.5 & 67.5 & 65.4 & 80.0 & 71.3 & 66.3 & 72.1 & 70.8 & 77.5 \\
\hline $\mathrm{VR}, \mathrm{SS}, \mathrm{SM}$ & 66.7 & 50.8 & 64.6 & 55.8 & 58.3 & 74.2 & 62.9 & 66.3 & 62.9 & 68.3 & 77.9 & 60.4 & 73.3 & 75.4 & 83.3 \\
\hline VR, SM, SK & 59.6 & 62.1 & 65.4 & 58.8 & 60.8 & 47.5 & 58.8 & 58.8 & 62.1 & 56.7 & 65.8 & 63.3 & 67.9 & 72.1 & 82.5 \\
\hline $\mathrm{VR}, \mathrm{SM}, \mathrm{KR}$ & 55.8 & 47.5 & 61.7 & 55.4 & 60.8 & 58.8 & 63.3 & 62.5 & 62.1 & 57.5 & 71.3 & 65.4 & 65.8 & 68.3 & 81.7 \\
\hline $\mathrm{KR}, \mathrm{SP}, \mathrm{SS}$ & 56.7 & 42.1 & 54.2 & 60.4 & 58.3 & 57.9 & 60.4 & 65.4 & 66.7 & 69.2 & 71.3 & 67.1 & 72.1 & 72.9 & 80.8 \\
\hline $\mathrm{KR}, \mathrm{SM}, \mathrm{SK}$ & 62.1 & 62.5 & 60.8 & 62.9 & 64.2 & 54.2 & 53.8 & 57.1 & 55.8 & 55.0 & 77.5 & 66.3 & 70.4 & 74.6 & 75.8 \\
\hline SS, SM, SK & 59.6 & 60.0 & 66.7 & 59.6 & 60.8 & 47.5 & 57.1 & 51.7 & 61.7 & 65.0 & 65.8 & 66.3 & 68.3 & 78.3 & 85.8 \\
\hline SS, SK, KR & 62.1 & 55.0 & 55.0 & 63.8 & 48.3 & 54.2 & 55.0 & 57.9 & 65.0 & 67.5 & 77.5 & 71.3 & 73.8 & 73.8 & 80.8 \\
\hline $\mathrm{SS}, \mathrm{SM}, \mathrm{KR}$ & 55.8 & 46.7 & 62.9 & 58.3 & 56.7 & 58.8 & 56.7 & 64.6 & 64.2 & 65.0 & 71.3 & 70.8 & 70.4 & 77.1 & 86.7 \\
\hline SS, SK, VR & 59.6 & 58.8 & 59.2 & 58.8 & 58.3 & 47.5 & 64.2 & 68.3 & 63.8 & 64.2 & 65.8 & 64.2 & 74.2 & 74.2 & 80.0 \\
\hline SK, VR, KR & 62.1 & 59.2 & 58.3 & 58.3 & 64.2 & 54.2 & 60.4 & 65.0 & 61.3 & 60.0 & 77.5 & 68.8 & 70.8 & 70.4 & 77.5 \\
\hline SK, SP, KR & 62.1 & 60.0 & 59.2 & 63.8 & 62.5 & 54.2 & 59.2 & 60.0 & 50.0 & 58.3 & 77.5 & 67.9 & 72.9 & 73.3 & 75.8 \\
\hline SK, VR, SP & 59.6 & 57.5 & 53.3 & 57.1 & 60.8 & 47.1 & 59.6 & 62.9 & 62.1 & 52.5 & 64.2 & 60.4 & 67.9 & 71.3 & 80.0 \\
\hline
\end{tabular}

Table 5 Classification accuracies of 9-subjects across 6-filters using 6-feature combination for 6-classifiers

\begin{tabular}{|c|c|c|c|c|c|c|c|c|c|c|c|c|c|c|c|}
\hline \multirow[t]{3}{*}{ Filter } & \multicolumn{15}{|c|}{ Accuracy (\%) } \\
\hline & \multicolumn{5}{|l|}{$\begin{array}{l}\text { S1 } \\
\text { S2 } \\
\text { S3 } \\
\end{array}$} & \multicolumn{5}{|l|}{$\begin{array}{l}\text { S4 } \\
\text { S5 } \\
\text { S6 } \\
\end{array}$} & \multicolumn{5}{|l|}{$\begin{array}{l}57 \\
\text { S8 } \\
59 \\
\end{array}$} \\
\hline & KNN & LDA & QDA & NB & SVM & KNN & LDA & QDA & NB & SVM & KNN & LDA & QDA & NB & SVM \\
\hline \multirow[t]{3}{*}{$\mathrm{FIR}$} & 56.7 & 60.8 & 61.3 & 64.6 & 55.0 & 55.0 & 59.2 & 66.3 & 62.9 & 59.2 & 59.6 & 57.5 & 60.0 & 59.6 & 64.2 \\
\hline & 65.0 & 50.4 & 67.9 & 57.5 & 63.3 & 56.7 & 62.1 & 62.5 & 62.5 & 58.3 & 50.4 & 61.7 & 63.3 & 63.8 & 53.3 \\
\hline & 59.2 & 60.8 & 52.1 & 53.8 & 62.5 & 61.7 & 60.0 & 58.3 & 52.5 & 50.0 & 56.7 & 69.2 & 74.2 & 71.3 & 67.5 \\
\hline \multirow[t]{3}{*}{ hrf } & 57.9 & 62.2 & 69.2 & 68.3 & 77.5 & 63.3 & 65.8 & 63.3 & 64.2 & 74.2 & 67.1 & 61.3 & 64.6 & 65.0 & 65.0 \\
\hline & 67.1 & 60.4 & 75.8 & 70.8 & 72.5 & 60.0 & 61.2 & 67.1 & 60.8 & 73.3 & 51.7 & 72.1 & 72.9 & 62.9 & 76.7 \\
\hline & 62.1 & 63.8 & 67.5 & 55.8 & 68.3 & 54.2 & 60.4 & 71.7 & 59.2 & 80.8 & 77.5 & 68.8 & 80.0 & 73.3 & 86.7 \\
\hline \multirow[t]{3}{*}{ Gaussian } & 56.7 & 59.2 & 53.8 & 62.5 & 65.0 & 54.2 & 52.1 & 55.0 & 57.9 & 55.8 & 57.1 & 53.8 & 48.3 & 57.5 & 54.2 \\
\hline & 50.0 & 55.8 & 52.5 & 61.7 & 58.3 & 52.1 & 50.0 & 52.1 & 58.8 & 60.0 & 55.8 & 55.0 & 53.3 & 60.4 & 55.0 \\
\hline & 52.1 & 59.6 & 50.8 & 54.2 & 57.5 & 55.4 & 60.0 & 64.2 & 57.1 & 54.2 & 48.8 & 57.5 & 59.2 & 61.7 & 61.7 \\
\hline \multirow[t]{3}{*}{ Kalman } & 51.3 & 57.1 & 52.5 & 64.2 & 65.0 & 53.8 & 53.3 & 52.9 & 54.2 & 51.7 & 47.1 & 56.7 & 55.0 & 57.9 & 60.8 \\
\hline & 53.3 & 46.7 & 55.0 & 60.4 & 54.2 & 52.5 & 48.8 & 49.6 & 59.2 & 47.5 & 51.3 & 60.0 & 57.1 & 60.0 & 51.7 \\
\hline & 55.4 & 57.9 & 47.9 & 52.1 & 55.0 & 60.4 & 57.1 & 62.5 & 57.5 & 50.0 & 56.7 & 57.5 & 64.6 & 61.3 & 57.5 \\
\hline \multirow[t]{3}{*}{ Wiener } & 60.0 & 52.9 & 57.9 & 63.8 & 65.8 & 57.9 & 55.4 & 60.0 & 57.1 & 65.0 & 55.4 & 57.5 & 63.3 & 62.9 & 70.8 \\
\hline & 59.2 & 62.5 & 70.8 & 63.3 & 68.3 & 51.3 & 55.8 & 59.6 & 56.7 & 70.0 & 54.6 & 62.9 & 65.0 & 64.6 & 72.5 \\
\hline & 52.9 & 59.6 & 56.7 & 58.8 & 65.0 & 55.0 & 57.5 & 59.6 & 63.3 & 60.8 & 62.1 & 60.4 & 70.0 & 70.0 & 78.3 \\
\hline \multirow[t]{3}{*}{ Butterworth } & 55.4 & 60.8 & 60.0 & 62.9 & 65.0 & 49.2 & 55.4 & 63.3 & 59.6 & 53.3 & 56.3 & 56.7 & 60.4 & 62.5 & 55.8 \\
\hline & 60.0 & 57.5 & 67.1 & 65.0 & 63.3 & 54.2 & 55.4 & 64.2 & 59.6 & 65.0 & 52.9 & 60.0 & 61.7 & 62.9 & 63.3 \\
\hline & 48.8 & 59.2 & 56.3 & 52.1 & 57.5 & 43.8 & 60.0 & 64.2 & 67.1 & 55.8 & 62.1 & 63.8 & 63.8 & 60.8 & 63.3 \\
\hline
\end{tabular}


Table 6 Statistical significances of classifiers

\begin{tabular}{ll}
\hline Classifiers & $p$-values \\
\hline KNN vs. LDA/QDA/NB/SVM & $0.158,0.016,0.158,0.009$ \\
LDA vs. QDA/NB/SVM & $0.009,0.369,0.001$ \\
QDA vs. NB/SVM & $0.047,0.009$ \\
NB vs. SVM & 0.002 \\
\hline
\end{tabular}

last updated position. In order to return the lower limb to its initial state with the rest intention, a methodology that incurs shorter computation and execution time needs to be developed.

\section{Conclusion}

The aims of this study were to use an optimal filter and classifier to obtain the maximum accuracy for given data and to implement a gait control scheme for a lower limb. To those ends, fNIRS signals were acquired from the primary motor cortex (M1) in the left hemisphere of the brain. For removal of physiological and instrumental noises, six filters (i.e. Kalman, Wiener, Gaussian,

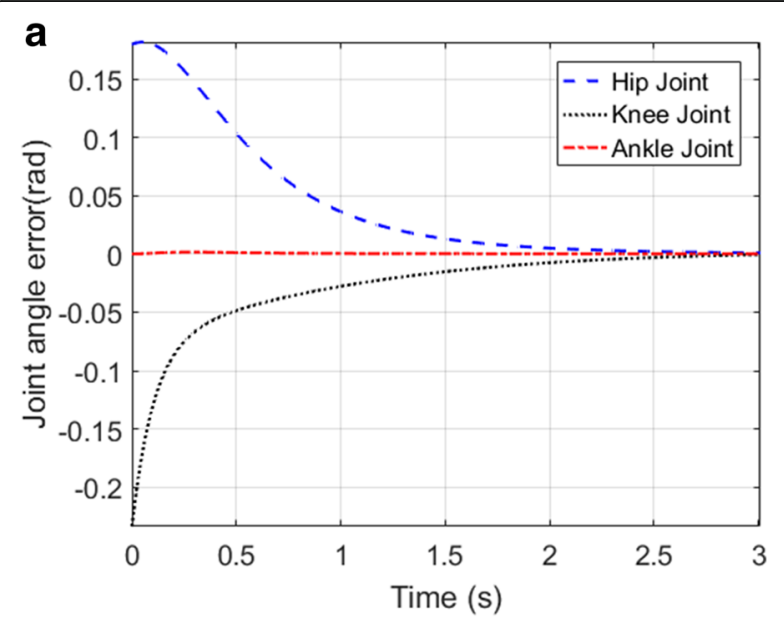

\section{b}

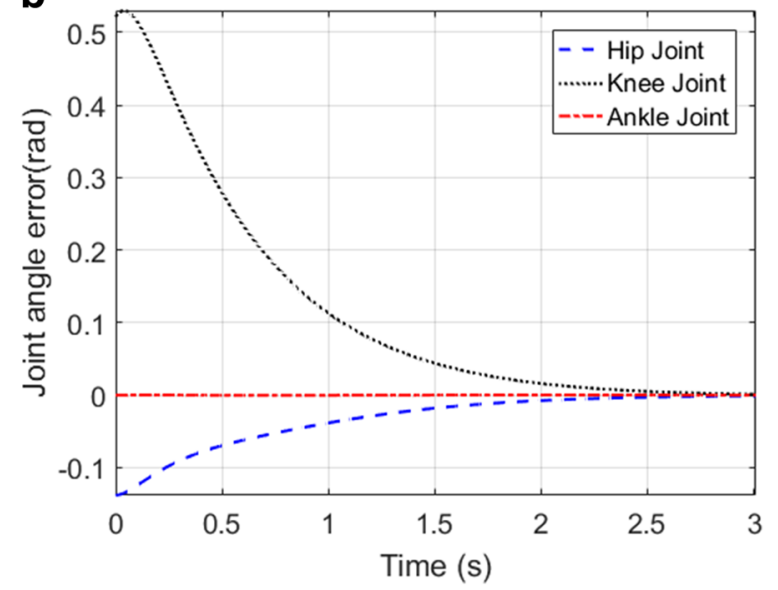

Fig. 10 Joint-angle error plot of left leg (a) and right leg (b)
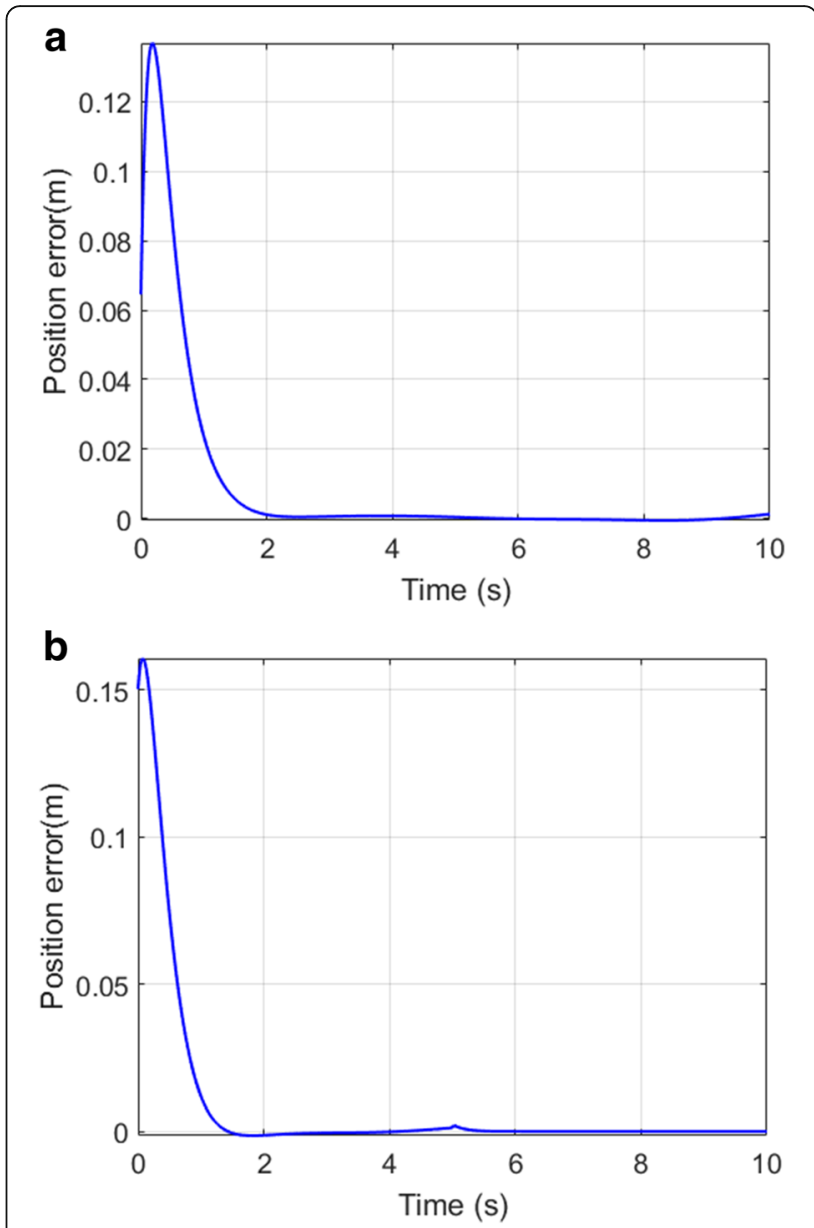

Fig. 11 Tool tip position-error plot of left leg (a) and right leg (b)

hemodynamic response (hrf), Band-pass, finite impulse response (FIR)) were used with the five classifiers QDA, LDA, SVM, KNN and NB. Brain intention was used to generate trigger commands, while the computed torque controller (CTC) was used to reduce position error. For brain-signal classification, six-feature (i.e. SS, SP, SM, KR, SV, SK) combinations were used. An average accuracy of $75 \%$ was obtained using the SVM offline classifier with hrf. For rehabilitation purposes, online classification was performed using LDA. To avoid false triggering, the testing trial was divided into 10 further subsections, and each subsection was separately classified. The triggering command was generated based on a $90 \%$ average accuracy benchmark for classified sections. In the second part of this study, a proposed prosthetic leg model was derived that is non-linear in nature; thus, it was determined that the nonlinear characteristics of the system could not be ignored. Therefore, instead of applying linearization to solve this problem approximately, we utilized the PD-CTC with guaranteed global asymptotic stability. The proposed prosthetic leg model was more deeply explored using the Euler Lagrange approach. A 


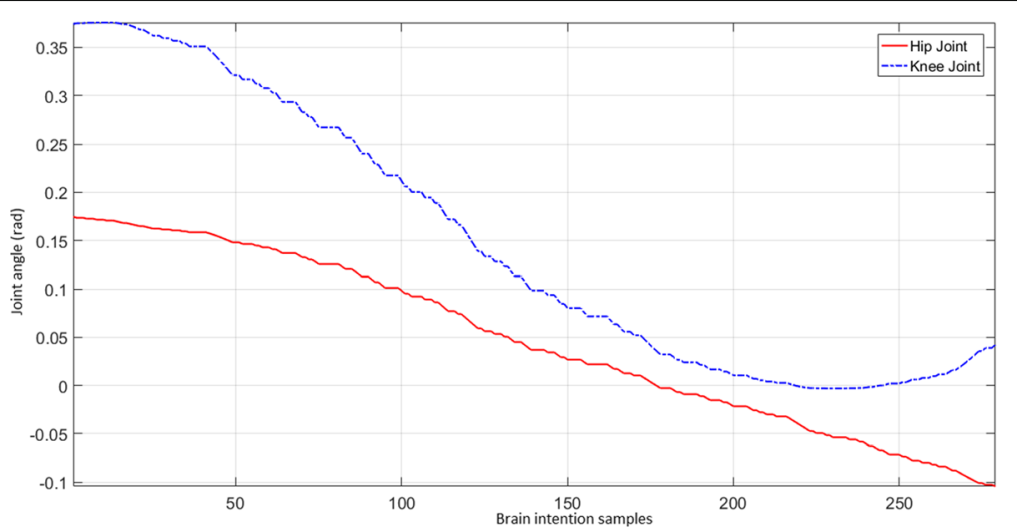

Fig. 12 Brain intention versus joint angles for Subject 1

simple PD-CTC independent joint controller was utilized for the hip and knee joints so that the manipulator retained its nonlinear characteristics. The simulation results confirmed that the asymptotic stability of the system can be reached in a finite time, as the determined position accuracy was satisfactory. Possible extension of this work would entail increasing the number of BCI classes for exploration of the gait patterns of persons of different age groups. Another interesting aspect could be exploring the relevance of individual channels with the task. Using features from more relevant channels for classification might also increase the classification accuracy.

\section{Acknowledgments}

We would like to thank Prof. Keum-Shik Hong from Pusan National University for providing us an opportunity to visit his lab and use the equipment therein for data acquisition.

\section{Funding}

Not applicable

Availability of data and materials

Please contact author for data requests.

\section{Authors' contributions}

RK conceived this study and was involved in the experiments, data processing, and writing of the manuscript. $\mathrm{NQ}, \mathrm{FN}$ and $\mathrm{HN}$ were involved in data analysis. MK was involved in data analysis and rechecking of results. NN was involved in the writing of the manuscript and supervised the entire research. All authors read and approved the final manuscript.

\section{Ethics approval and consent to participate}

Prior to the experimentation, verbal consent was obtained from all of the subjects. All experiments were approved by the institutional review board of Pusan National University and were performed in accordance with latest Declaration of Helsinki.

\section{Consent for publication}

Consent from all authors has been acquired prior to submission of this article.

\section{Competing interests}

The authors declare that they have no competing interests.

\section{Publisher's Note}

Springer Nature remains neutral with regard to jurisdictional claims in published maps and institutional affiliations.

\section{Author details}

${ }^{1}$ Department of Mechatronics Engineering, Air University, Islamabad, Pakistan. ${ }^{2}$ Department of Biomedical Engineering, Faculty of Electronic Information and Electrical Engineering, Dalian University of Technology, Dalian, China. ${ }^{3}$ Department of Electrical and Computer Engineering, Institute of Systems and Robotics, University of Coimbra, Coimbra, Portugal.

Received: 20 October 2017 Accepted: 17 January 2018

Published online: 05 February 2018

\section{References}

1. Duncan PW, Sullivan KJ, Behrman AL, Azen SP, Wu SS, Nadeau SE, et al. Body-weight-supported treadmill rehabilitation after stroke. N Engl J Med. 2011;364:2026-36.

2. Belda-Lois J-M, Mena-del Horno S, Bermejo-Bosch I, Moreno JC, Pons JL, Farina $D$, et al. Rehabilitation of gait after stroke: a review towards a top-down approach. J Neuroeng Rehabil BioMed Central Ltd. 2011;8:66.

3. Velliste M, Perel S, Spalding MC, Whitford AS, Schwartz AB. Cortical control of a prosthetic arm for self-feeding. Nature. 2008:453:1098-101.

4. Naseer N, Hong K-S. fNIRS-based brain-computer interfaces: a review. Front Hum Neurosci. 2015;9:1-15.

5. Mao Y-R, Lo WL, Lin Q, Li L, Xiao X, Raghavan P, et al. The effect of body weight support treadmill training on gait recovery, proximal lower limb motor pattern, and balance in patients with subacute stroke. Biomed Res Int. 2015;2015:1-10.

6. Pohl M, Werner C, Holzgraefe M, Kroczek G, Wingendorf I, Hoölig G, et al. Repetitive locomotor training and physiotherapy improve walking and basic activities of daily living after stroke: a single-blind, randomized multicentre trial (DEutsche GAngtrainerStudie, DEGAS). Clin Rehabil. 2007:21:17-27.

7. Banala SK, Kim SH, Agrawal SK, Scholz JP. Robot assisted gait training with active leg exoskeleton (ALEX). IEEE Trans Neural Syst Rehabil Eng IEEE. 2009;17:2-8.

8. van der Kooij H, Koopman B, van Asseldonk EHF. Body weight support by virtual model control of an impedance controlled exoskeleton (LOPES) for gait training. 30th Annu Int Conf IEEE Eng Med Biol Soc IEEE. 2008;2008:1969-72.

9. Huppert TJ. Commentary on the statistical properties of noise and its implication on general linear models in functional near-infrared spectroscopy. Neurophotonics. 2016;3:10401.

10. Kamran MA, Hong K-S. Reduction of physiological effects in fNIRS waveforms for efficient brain-state decoding. Neurosci. Lett. Elsevier Ireland Ltd. 2014:580:130-6.

11. Kamran MA, Hong K-S. Linear parameter-varying model and adaptive filtering technique for detecting neuronal activities: an fNIRS study. J Neural Eng. 2013;10:56002. 
12. Cooper RJ, Gagnon L, Goldenholz DM, Boas DA, Greve DN. The utility of near-infrared spectroscopy in the regression of low-frequency physiological noise from functional magnetic resonance imaging data. Neurolmage. 2012;59:3128-38.

13. Aqil M, Hong K-S, Jeong M-Y, Ge SS. Detection of event-related hemodynamic response to neuroactivation by dynamic modeling of brain activity. Neuroimage Elsevier Inc. 2012;63:553-68.

14. Aqil M, Hong $\mathrm{K}-\mathrm{S}$, Jeong $\mathrm{M}-\mathrm{Y}, \mathrm{G}$ GS. Cortical brain imaging by adaptive filtering of NIRS signals. Neurosci. Lett. Elsevier Ireland Ltd. 2012;514:35-41.

15. Abdelnour $A F$, Huppert $T$. Real-time imaging of human brain function by near-infrared spectroscopy using an adaptive general linear model. Neurolmage. 2009;46:133-43.

16. Cope M, Delpy DT. System for long-term measurement of cerebral blood and tissue oxygenation on newborn infants by near infra-red transillumination. Med Biol Eng Comput. 1988:26:289-94.

17. Ye J, Tak S, Jang K, Jung J, Jang J. NIRS-SPM: statistical parametric mapping for near-infrared spectroscopy. Neurolmage Elsevier Inc. 2009;44:428-47.

18. Villringer A, Planck J, Hock C, Schleinkofer L, Dirnagl U. Near infrared spectroscopy (NIRS): a new tool to study hemodynamic changes during activation of brain function in human adults. Neurosci Lett. 1993;154:101-4.

19. Jobsis F. Noninvasive, infrared monitoring of cerebral and myocardial oxygen sufficiency and circulatory parameters. Science. 1977;198:1264-7.

20. Hong K-S, Naseer N, Kim Y-H. Classification of prefrontal and motor cortex signals for three-class fNIRS-BCI. Neurosci Lett Elsevier Ireland Ltd. 2015;587:87-92.

21. Nicolas-Alonso LF, Gomez-Gil J. Brain computer interfaces, a review. Sensors. 2012;12:1211-79.

22. Holtzer R, Mahoney JR, Izzetoglu M, Wang C, England S, Verghese J. Online fronto-cortical control of simple and attention-demanding locomotion in humans. Neurolmage. 2015;112:152-9.

23. Naseer N, Hong MJ, Hong K-S. Online binary decision decoding using functional near-infrared spectroscopy for the development of braincomputer interface. Exp Brain Res. 2014;232:555-64.

24. Brigadoi S, Ceccherini L, Cutini S, Scarpa F, Scatturin P, Selb J, et al, Motion artifacts in functional near-infrared spectroscopy: a comparison of motion correction techniques applied to real cognitive data. Neurolmage. 2014;85:181-91.

25. Bauernfeind G, Wriessnegger SC, Daly I, Muller-Putz GR. Separating heart and brain: on the reduction of physiological noise from multichannel functional near-infrared spectroscopy (fNIRS) signals. J Neural Eng IOP Publishing. 2014;11:56010.

26. Tak S, Ye JC. Statistical analysis of fNIRS data: a comprehensive review. Neurolmage Elsevier Inc. 2014;85:72-91.

27. García-Cossio E, Severens M, Nienhuis B, Duysens J, Desain P, Keijsers N, et al. Decoding Sensorimotor rhythms during robotic-assisted treadmill walking for brain computer Interface (BCI) applications. Ivanenko YP, editor. PLoS One. 2015;10:e0137910.

28. Sburlea Al, Montesano L, de la Cuerda RC, Alguacil Diego IM, MiangolarraPage JC, Minguez J. Detecting intention to walk in stroke patients from pre-movement EEG correlates. J. Neuroeng. Rehabil. 2015;12:113.

29. Naseer N, Hong K-S. Classification of functional near-infrared spectroscopy signals corresponding to the right- and left-wrist motor imagery for development of a brain-computer interface. Neurosci Lett. 2013;553:84-9.

30. Rea M, Rana M, Lugato N, Terekhin P, Gizzi L, Brötz D, et al. Lower limb movement preparation in chronic stroke. Neurorehabil Neural Repair. 2014;28:564-75.

31. Zhao H, Horn J, Reher J, Paredes V, Ames AD. First steps toward translating robotic walking to prostheses: a nonlinear optimization based control approach. Auton. Robots. Springer US. 2017;41:725-42.

32. Azimi $V$, Simon D, Richter $\mathrm{H}$. Stable robust adaptive impedance control of a prosthetic leg. Adapt Intell Syst Control Adv Control Des Methods; Adv Non-Linear Optim Control Adv Robot Adv Wind Energy Syst Aerosp Appl Aerosp Power Optim Assist Robo ASME. 2015;1:V001T09A003.

33. Richter H, Simon D, Smith WA, Samorezov S. Dynamic modeling, parameter estimation and control of a leg prosthesis test robot. Appl Math Model Elsevier Inc. 2015:39:559-73.

34. Perrey S. Possibilities for examining the neural control of gait in humans with fNIRS. Front Physiol. 2014;5:10-3.

35. Venkatakrishnan A, Francisco GE, Contreras-Vidal JL. Applications of brainmachine Interface Systems in Stroke Recovery and Rehabilitation. Curr Phys Med Rehabil Reports. 2014;2:93-105.
36. Kirlilna E, Yu N, Jelzow A, Wabnitz H, Jacobs AM, Tachtsidis I. Identifying and quantifying main components of physiological noise in functional near infrared spectroscopy on the prefrontal cortex. Front Hum Neurosci. 2013;7:1-17.

37. Xie H, Kang G, Li F. The design and control simulation of trans-femoral prosthesis based on virtual prototype. Int J Hybrid Inf Technol. 2013;6:91-100.

38. Neogi B, Darbar R, Mondal S, Gorai B, Ghosh S, Das A, et al. Study of proper tuning of prosthetic limb control system with paraplegia and fatigue condition. Second Int Conf Emerg Appl Inf Technol IEEE. 2011;2011:79-82.

39. Petric T, Gams A, Debevec T, Zlajpah L, Babic J. Control approaches for robotic knee exoskeleton and their effects on human motion. Adv Robot. 2013;27:993-1002.

40. Corke P. Robotics, vision and control. Berlin: Springer Berlin Heidelberg; 2011.

41. Miyai I, Tanabe HC, Sase I, Eda H, Oda I, Konishi I, et al. Cortical mapping of gait in humans: a near-infrared spectroscopic topography study. Neurolmage. 2001;14:1186-92.

42. Pfurtscheller G, Leeb R, Keinrath C, Friedman D, Neuper C, Guger C, et al. Walking from thought. Brain Res. 2006;1071:145-52.

43. Mihara M, Miyai I, Hatakenaka M, Kubota K, Sakoda S. Role of the prefrontal cortex in human balance control. Neurolmage. 2008;43:329-36.

44. Lotte F, Congedo M, Lécuyer A, Lamarche F, Arnaldi B. A review of classification algorithms for EEG-based brain-computer interfaces. J Neural Eng. 2007;4:R1-13.

45. Grimble MJ. Robust industrial control systems. Chichester: John Wiley \& Sons Ltd; 2006.

46. Kostiev AY, Butrym AY, Shulga SN. Time-varying wiener filtering based on short-time fourier transform, 2012 6th Int. conf. Ultrawideband Ultrashort Impuls. Signals. IEEE; 2012. p. 305-8.

47. Naseer N, Noori FM, Qureshi NK, Hong K. Determining optimal featurecombination for LDA classification of functional near-infrared spectroscopy signals in brain-computer Interface application. Front Hum Neurosci. 2016;10:1-10.

48. Sitaram R, Zhang H, Guan C, Thulasidas M, Hoshi Y, Ishikawa A, et al. Temporal classification of multichannel near-infrared spectroscopy signals of motor imagery for developing a brain-computer interface. Neurolmage. 2007;34:1416-27.

49. Hu X-S, Hong K-S, Ge SS. fNIRS-based online deception decoding. J Neural Eng. 2012;9:26012

50. Abibullaev B, An J. Classification of frontal cortex haemodynamic responses during cognitive tasks using wavelet transforms and machine learning algorithms. Med Eng Phys Institute of Physics and Engineering in Medicine. 2012;34:1394-410.

51. Burges CJC. A tutorial on support vector machines for pattern recognition. Data Min Knowl Discov. 1998;2:121-67.

52. Tai K, Chau T. Single-trial classification of NIRS signals during emotional induction tasks: towards a corporeal machine interface. J. Neuroeng. Rehabil. 2009;6:39

53. Luu S, Chau T. Decoding subjective preference from single-trial nearinfrared spectroscopy signals. J Neural Eng. 2009;6:16003.

54. Kim KS, Choi HH, Moon CS, Mun CW. Comparison of k-nearest neighbor, quadratic discriminant and linear discriminant analysis in classification of electromyogram signals based on the wrist-motion directions. Curr Appl Phys Elsevier B.V. 2011;11:740-5.

55. Naseer N, Qureshi NK, Noori FM, Hong K. Analysis of different classification techniques for two-class functional near-infrared spectroscopy-based braincomputer Interface. Comput Intell Neurosci. 2016:2016:1-11.

56. Poliakov. Transfemoral prosthesis with polycentric knee mechanism: design, kinematics, dynamics and control strategy. J Rehabil Robot. 2013;38:109-23.

57. Mak AF, Zhang M, Boone DA. State-of-the-art research in lower-limb prosthetic biomechanics-socket interface: a review. J Rehabil Res Dev. 2001;38:161-74

58. Gams A, Petric T, Debevec T, Babic J. Effects of robotic knee exoskeleton on human energy expenditure. IEEE Trans Biomed Eng. 2013;60:1636-44.

59. Miller LA, Childress DS. Problems associated with the use of inverse dynamics in prosthetic applications: an example using a polycentric prosthetic knee. Robotica. 2005;23:329-35.

60. Narang YS. Identification of design requirements for a high-performance, low-cost, passive prosthetic knee through user analysis and dynamic simulation by. 2013. p. 1-98.

61. Unal R, Carloni R, Hekman EEG, Stramigioli S, Koopman HFJM. Biomechanical conceptual design of a passive transfemoral prosthesis. Annu Int Conf IEEE Eng Med Biol IEEE. 2010;2010:515-8. 
62. An CH, Atkeson CG, Griffiths JD, Hollerbach JM. Experimental evaluation of feedforward and computed torque control. IEEE Trans Robot Autom. 1989;5:368-73.

63. Nanjangud A, Gregg RD. Simultaneous control of an ankle-foot prosthesis model using a virtual constraint. Act Control Aerosp Struct Motion Contro Aerosp Control Assist Robot Syst Bio-Inspired Syst Biomed Appl Build Energy Syst Cond Based Monit Control Des Drill A ASME. 2014;1:V001T04A001.

64. Rameez M, Khan LA. Modeling and dynamic analysis of the biped robot. 15th Int Conf Control Autom Syst IEEE. 2015;2015:1149-53.

65. Omer A, Hashimoto K, Lim H-O, Takanishi A. Study of bipedal robot walking motion in low gravity: investigation and analysis. Int J Adv Robot Syst. 2014;11:139.

66. Gay S, van den Kieboom J, Santos-Victor J, ljspeert AJ. Model-based and model-free approaches for postural control of a compliant humanoid robot using optical flow. 13th IEEE-RAS Int Conf Humanoid Robot IEEE. 2013;2013:56-61.

67. Ai Q, Ding B, Liu Q, Meng W. A subject-specific EMG-driven musculoskeletal model for applications in lower-limb rehabilitation robotics. Int J Humanoid Robot. 2016;13:1650005.

68. Craig JJ. Introduction to robotics: mechanics and control 3rd. Prentice Hall. 2004;1:408.

69. Windrich M, Grimmer M, Christ O, Rinderknecht S, Beckerle P. Active lower limb prosthetics: a systematic review of design issues and solutions. Biomed Eng Online. 2016;15:140.

70. Baser O, Keskin O, Cetin L, Uyar E. Computing the torque demand of a prosthetic leg. In Annals of DAAAM for 2011 and Proceedings of the 22nd International DAAAM Symposium "Intelligent Manufacturing and Automation: Power of Knowledge and Creativity". DAAAM. 2011:1726-9679.

71. Jean F, Bergevin R, Branzan Albu A. Human gait characteristics from unconstrained walks and viewpoints. IEEE Int Conf Comput Vis Work ICCV Work. IEEE. 2011;2011:1883-8.

72. Schulze M, Tsung-Han Liu, Jiang Xie, Wu Zhang, Wolf K-H, Calliess T, et al. Unobtrusive ambulatory estimation of knee joint angles during walking using gyroscope and accelerometer data - a preliminary evaluation study. Proc. 2012 IEEE-EMBS Int. conf. Biomed. Heal. Informatics. IEEE; 2012. p. 559-62.

73. Oberg T, Karsznia A, Oberg K. Joint angle parameters in gait: reference data for normal subjects, 10-79 years of age. J Rehabil Res Dev. 1994;31:199-213.

74. Sankaran J. Real-time computed torque control of flexible-joint robots. Control. 1997;1997:1-191.

75. Piltan F, Mirzaie M, Shahriyari F, Nazari I, Emamzadeh S. Design baseline computed torque controller. Int J Eng. 2012;6:129-41.

76. Gregg RD, Lenzi T, Hargrove LJ, Sensinger JW. Virtual constraint control of a powered prosthetic leg: from simulation to experiments with Transfemoral amputees. IEEE Trans Robot. 2014;30:1455-71.

77. Zhao H, Horn J, Reher J, Paredes V, Ames AD. First steps toward translating robotic walking to prostheses: a nonlinear optimization based control approach. Auton Robots. 2017:41:725-42.

78. Gams A, van den Kieboom J, Dzeladini F, Ude A, ljspeert AJ. Real-time full body motion imitation on the COMAN humanoid robot. Robotica. 2015;33:1049-61.

79. Faraji S, Pouya S, ljspeert A. Robust 3D walking using inverse dynamics and footstep planning with model predictive control, 9th Dyn. Walk. Conf; 2014. p. 1-2.

80. Qureshi NK, Naseer N, Noori FM, Nazeer H, Khan RA, Saleem S. Enhancing classification performance of functional near-infrared spectroscopy- braincomputer Interface using adaptive estimation of general linear model coefficients. Front Neurorobot. 2017;11:33.

81. Noori FM, Naseer N, Qureshi NK, Nazeer H, Khan RA. Optimal feature selection from fNIRS signals using genetic algorithms for $\mathrm{BCl}$. Neurosci Lett Elsevier Ireland Ltd. 2017;647:61-6.

82. Hong K-S, Naseer N. Reduction of delay in detecting initial dips from functional near-infrared spectroscopy signals using vector-based phase analysis. Int J Neural Syst. 2016;26:1650012.

83. Naseer N, Hong K-S. Decoding answers to four-choice questions using functional near infrared spectroscopy. J Near Infrared Spectrosc. 2015;23:23.

84. Vitorio $R$, Stuart $S$, Rochester $L$, Alcock $L$, Pantall A. fNIRS response during walking - Artefact or cortical activity? A systematic review. Neurosci Biobehav Rev. 2017;83:160-72.

85. Power SD, Falk TH, Chau T. Classification of prefrontal activity due to mental arithmetic and music imagery using hidden Markov models and frequency domain near-infrared spectroscopy. J Neural Eng. 2010;7:26002.
86. Holper $L$, Wolf M. Single-trial classification of motor imagery differing in task complexity: a functional near-infrared spectroscopy study. J Neuroeng Rehabil. 2011;8:34

87. Faress A, Chau T. Towards a multimodal brain-computer interface: combining fNIRS and fTCD measurements to enable higher classification accuracy. Neurolmage Elsevier Inc. 2013;77:186-94.

88. Power SD, Chau T. Automatic single-trial classification of prefrontal hemodynamic activity in an individual with Duchenne muscular dystrophy. Dev Neurorehabil. 2012;16:1-6.

89. Power SD, Kushki A, Chau T. Towards a system-paced near-infrared spectroscopy brain-computer interface: differentiating prefrontal activity due to mental arithmetic and mental singing from the no-control state. J Neural Eng. 2011;8:66004.

90. Cui X, Bray S, Reiss AL. Speeded near infrared spectroscopy (NIRS) response detection. PLoS One. 2010:5:e15474.

91. Naito M, Michioka Y, Ozawa K, Ito Y, Kiguchi M, Kanazawa T. A communication means for totally locked-in ALS patients based on changes in cerebral blood volume measured with near-infrared light. IEICE Trans Inf Syst 2007;E90-D:1028-37.

92. Salvaris M, Sepulveda F. Classification effects of real and imaginary movement selective attention tasks on a P300-based brain-computer interface. J Neural Eng. 2010;7:56004.

93. Quang T, Khoa D, Nakagawa M. Functional near infrared spectroscope for cognition brain tasks by wavelets analysis and neural networks. Life Sci. 2008;1:28-33.

94. Biallas M, Trajkovic I, Haensse D, Marcar V, Wolf M. Reproducibility and sensitivity of detecting brain activity by simultaneous electroencephalography and near-infrared spectroscopy. Exp Brain Res. 2012;222:255-64.

95. Dare WN, Erefah AZ, Ogbe PD. A comparative study on thigh length to leg length ratio in adult males of two southern states in Nigeria. Eur J Appl Sci. 2013;5:115-7.

\section{Submit your next manuscript to BioMed Central and we will help you at every step:}

- We accept pre-submission inquiries

- Our selector tool helps you to find the most relevant journal

- We provide round the clock customer support

- Convenient online submission

- Thorough peer review

- Inclusion in PubMed and all major indexing services

- Maximum visibility for your research

Submit your manuscript at www.biomedcentral.com/submit
) Biomed Central 